\title{
Exploring Factors Affecting Persistence of First-Year Student Success at the University of the District of Columbia
}

Twyla L. Jones

West Virginia University

Follow this and additional works at: https://researchrepository.wvu.edu/etd

\section{Recommended Citation}

Jones, Twyla L., "Exploring Factors Affecting Persistence of First-Year Student Success at the University of the District of Columbia" (2011). Graduate Theses, Dissertations, and Problem Reports. 3100.

https://researchrepository.wvu.edu/etd/3100

This Dissertation is protected by copyright and/or related rights. It has been brought to you by the The Research Repository @WVU with permission from the rights-holder(s). You are free to use this Dissertation in any way that is permitted by the copyright and related rights legislation that applies to your use. For other uses you must obtain permission from the rights-holder(s) directly, unless additional rights are indicated by a Creative Commons license in the record and/ or on the work itself. This Dissertation has been accepted for inclusion in WVU Graduate Theses, Dissertations, and Problem Reports collection by an authorized administrator of The Research Repository @ WVU.

For more information, please contact researchrepository@mail.wvu.edu. 


\title{
Exploring Factors Affecting Persistence of First-Year Student Success at the University of the District of Columbia
}

\author{
Twyla L. Jones \\ Dissertation Submitted to the \\ College of Human Resources and Education \\ at West Virginia University \\ in partial fulfillment of the requirements \\ for the degree of \\ Doctor of Education \\ in \\ Educational Leadership Studies \\ Elizabeth A. Jones, Ph.D., Co-Chair \\ Scott Cottrell, Ed.D.,Co-Chair \\ Ernest Goeres, Ph.D. \\ Bertha D. Minus, Ph.D. \\ Richard Walls, Ph.D. \\ Department of Educational Leadership \\ Morgantown, West Virginia \\ 2011
}

Keywords: retention, students of color, historically black colleges and universities, first-year seminar, student engagement, academic advising, student involvement

Copyright 2011 Twyla L. Jones 


\begin{abstract}
Exploring Factors Affecting Persistence of First-Year Student Success at the University of the District of Columbia
\end{abstract}

Twyla L. Jones

This study examined four elements within the university environment that may provide a connection to the success of students' initial year on campus. The four elements are: freshman orientation course; academic advising and interaction with an advisor; involvement in student organizations, clubs, and athletics; and utilization of the university counseling center.

This study was based upon a survey administered during the months of March through May 2010 that examined the four areas of the university environment and the extent to which each student participated in each area. The population was 200 first-year students who had entered the university during the fall 2009 or spring 2010 semesters. Log-linear regression, chi-square, and frequency analysis were used to test four hypotheses related to student success and retention during the students' initial year.

Of the four null hypotheses tested, three were accepted, and one was rejected (freshman orientation course). Overall, there was high persistence for students who participated in each of the elements as well as for those who did not. Ultimately, none of the elements researched in this study were valid factors in predicting a student's persistence from their initial year to the fall 2010 semester.

Although this study did not identify those elements of the first-year experience that influence retention to the second year for UDC students, it does highlight the need for a better understanding of what students need in the academic environment in order to persist. Future research could include data relevant to student success in the course as opposed to mere enrollment in the course.

Future research may include a review of student achievement prior to enrollment. Further research on how to target services for retention may be a better way of improving retention and to have a better understanding of student satisfaction, student motivation, and student integration into the life of the institution.

Although the factors that help students to persist from their first semester to their second semester were not identified in this study, this does not mean that the exploration should not continue. Attention must be directed to the students' intent and expectations of the college experience and the services provided. For institutions, having a better understanding of what helps and what hinders students in their quest for success can assist in creating better road maps for students on their journey to degree completion. 


\section{Acknowledgements}

I would like to thank my family for walking this journey with me and encouraging me every step of the way. To my dear friends, I thank you for having an interest in a part of my life that so many will never understand, and I thank you for your patience as I continued this walk, over the years. This dissertation would not have been possible without the guidance of my dissertation committee. Thank you so much for your time and suggestions that went into completing my work. I am grateful to Drs. Cottrell and Jones for all of your assistance and suggestions. I am also grateful to Dr. Goeres for always adding his voice of reason to everything that might have been a challenge. Dr. Walls, thank you for helping to make this dissertation a better document. Thank you, Dr. Minus, for years of knowledge and tradition that you selflessly showered upon me throughout this process. A very special thank you is extended to Dr. Doris Johnson, Dr. Ernesta Williams, and Dr. Yates for your years of encouragement and words of constant advice. 


\section{Contents}

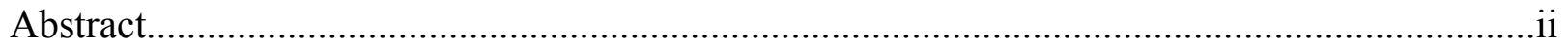

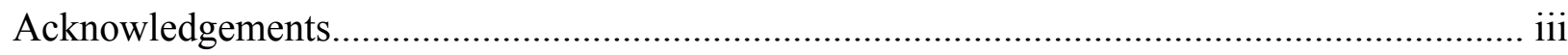

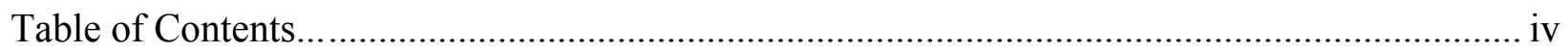

Chapter 1: Introduction and Statement of the Problem ........................................................... 1

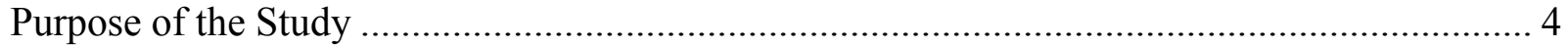

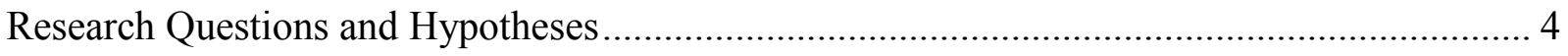

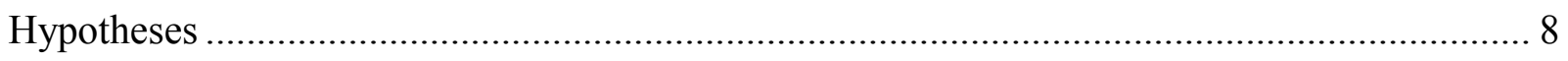

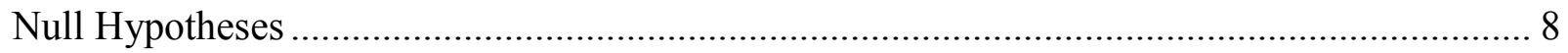

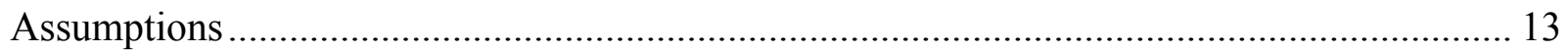

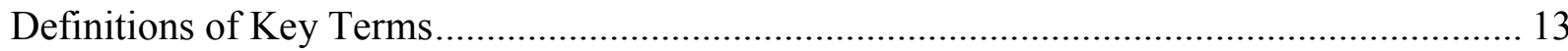

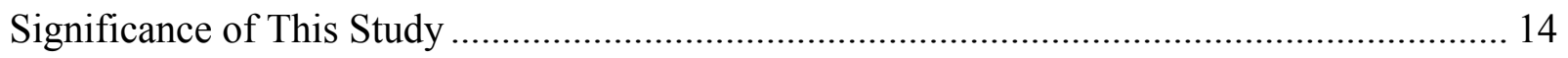

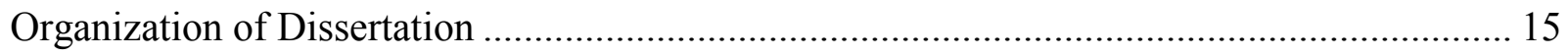

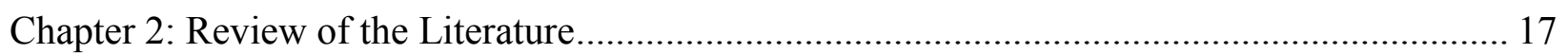

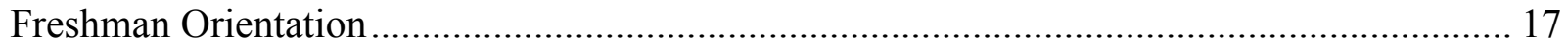

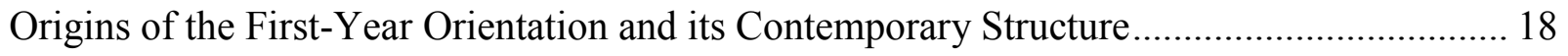

Rationale for the Existence of the Freshman Orientation Course ......................................... 21

Course Objectives and Varied Content Freshman Orientation Courses .............................. 22

Varied Types of Freshman Orientation Courses ............................................................. 22

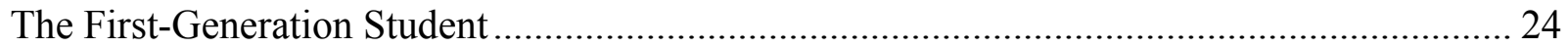




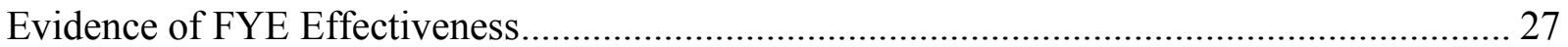

Lessons Learned from the First-Year Experience at the University of Texas at El Paso ......... 27

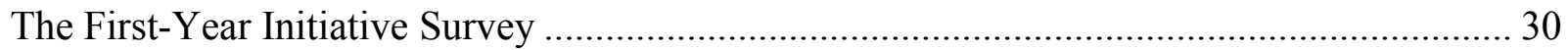

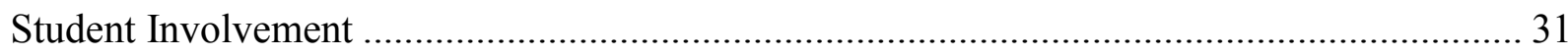

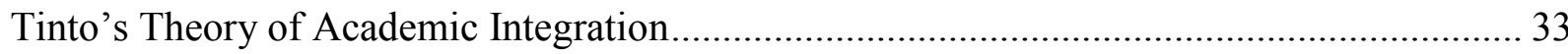

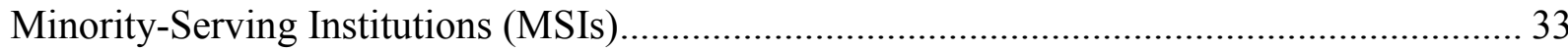

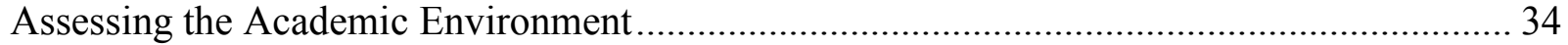

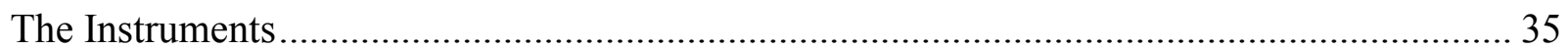

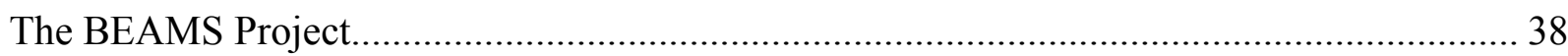

Creating an Environment for Involvement....................................................................... 40

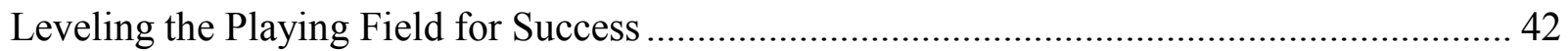

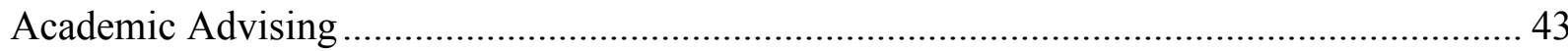

Developmental Advising vs. Prescriptive Advising ............................................................. 46

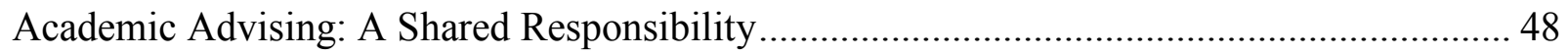

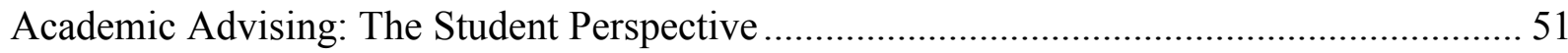

Academic Advising: Faculty Perspective …………………………………………….......... 53

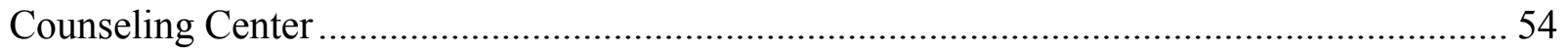

University of the District of Columbia's Counseling Center................................................... 56

Discussion of Student Interaction with Campus Counseling Centers...................................... 57

Retention Efforts and Appropriate Counseling Interventions................................................... 60 
Discussion of Appropriate Counseling Interventions, Programs, and Services...................... 61

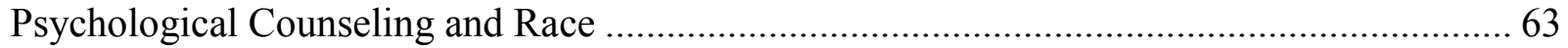

Coping Strategies Unique to the African-American Student Population................................ 67

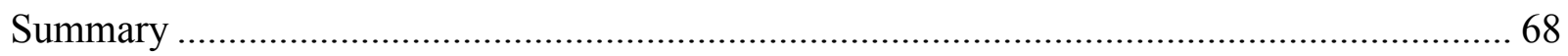

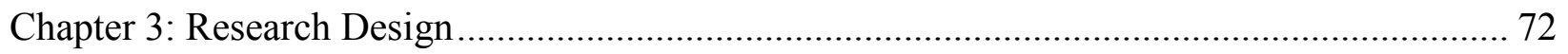

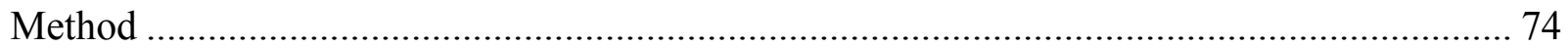

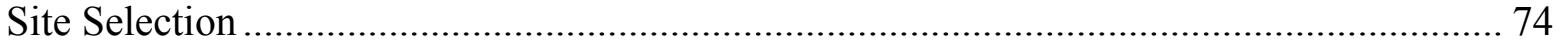

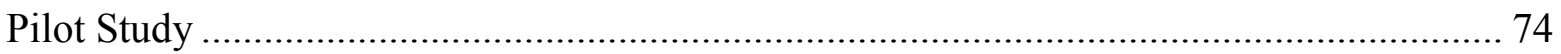

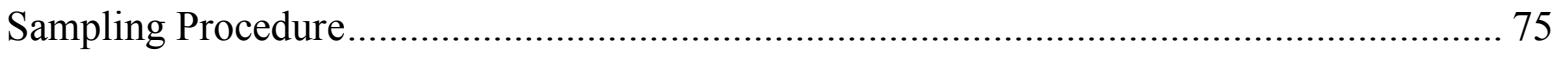

Strategy for Attaining Institutional Approval and Participant Cooperation ......................... 76

Description of the First-Year Experience Survey (FYES) ................................................ 77

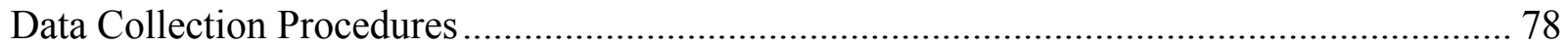

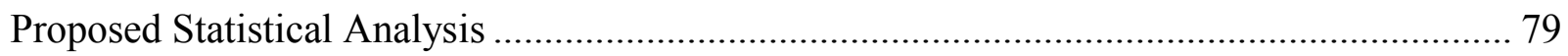

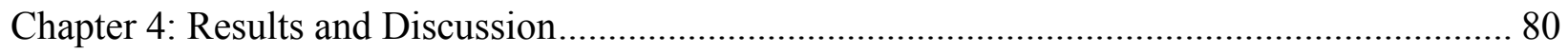

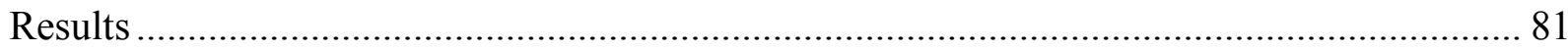

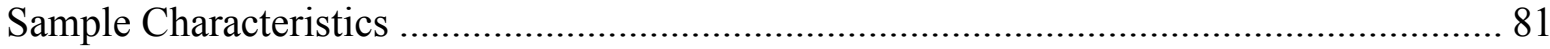

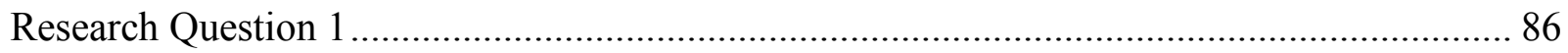

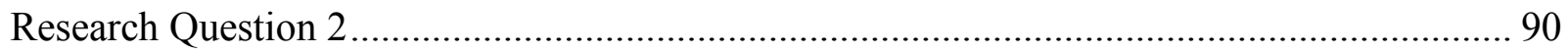

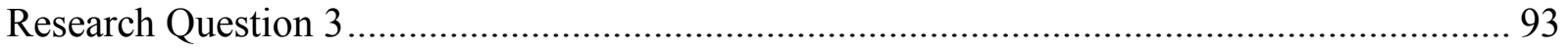

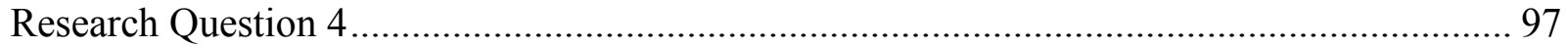


Chapter 5: Summary of Findings, Conclusions and Recommendations for Practice and Future

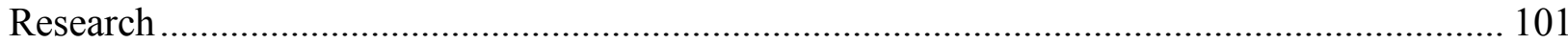

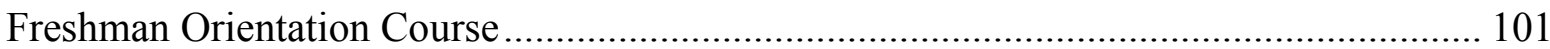

Involvement in a Student Club or Organization......................................................... 103

Utilization of the University Counseling Center .............................................................. 104

Student Interaction with Their Academic Advisor................................................... 105

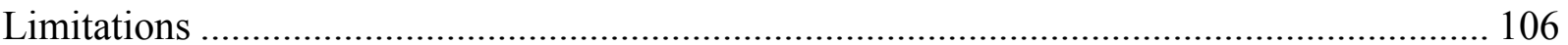

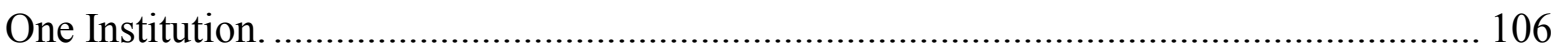

Benefits of Freshman Orientation Course Expected Too Soon...................................... 106

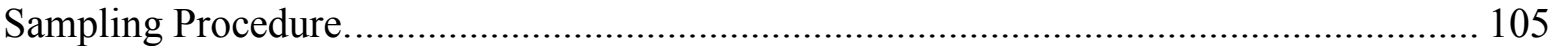

Survey Design Left Out Response Options .................................................................... 106

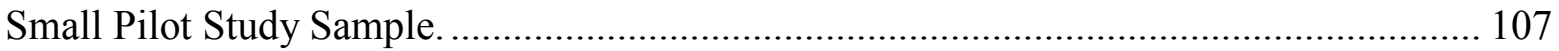

Freshman orientation course not limited to first year and new transfer students...........106

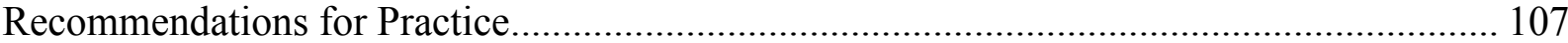

Recommendations for Future Research ................................................................... 108

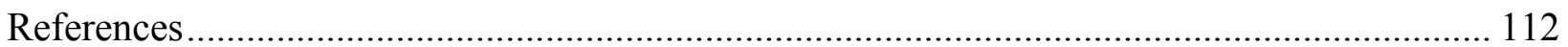

Appendix A WVU IRB Approval Letter .................................................................. 126

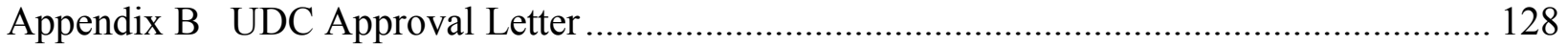

Appendix C First-Year Experience Survey …................................................................... 130 
Table of Tables

Table 1: First-to-Second-Year Retention of UDC Students 2005-2009 (Part-Time/Full-Time).. 11

Table 2: Survey Items 73

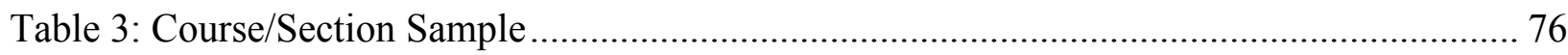

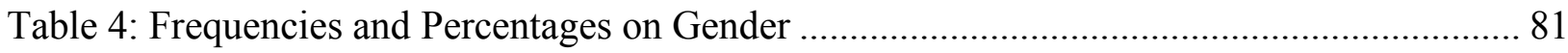

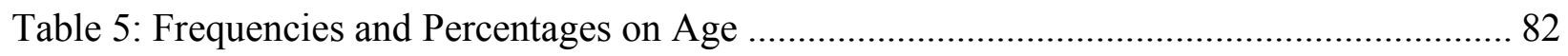

Table 6: Frequencies and Percentages on Race/Ethnicity ................................................ 82

Table 7: Frequencies and Percentages on Marital Status.................................................... 83

Table 8: Frequencies and Percentages on Employment and Immigration Status ...................... 83

Table 9: Frequencies and Percentages on Financial Aid Receipt and Current Credit Hours ....... 84

Table 10: Frequencies and Percentages on Number of Children under Age 18 ...................... 85

Table 11: Frequencies and Percentages of Participants Involved in Work Study ...................... 85

Table 12: Frequencies and Percentages of Students Enrolled in Freshman Orientation Course. 86

Table 13: Frequencies and Percentages of Usefulness of the Freshman Orientation Course....... 87

Table 14: Log-linear Parameter Index for Attending Freshman Orientation Course and Academic

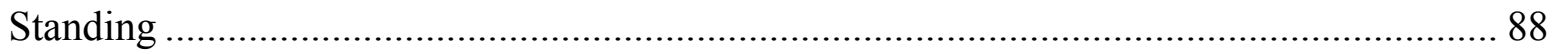

Table 15: Observed Frequencies and Percentages of Freshman Orientation Course and Academic

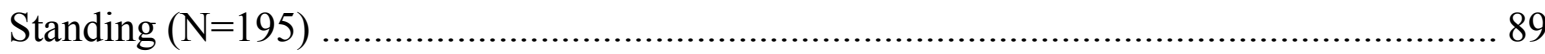

Table 16: Chi-Square on Usefulness of Freshman Orientation Course and Academic Success .. 90

Table 17: Frequencies and Percentages of Involvement in Club, Athletics,

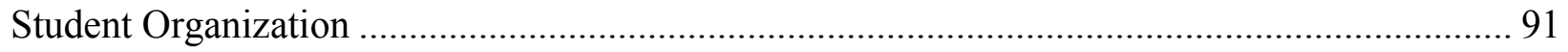

Table 18: Frequencies and Percentages of Increased Motivation to Remain at UDC ................ 91 
Table 19: Log-linear Parameter Estimates, Values, and Goodness-of-Fit Index on Belonging to a Club or Organization and Academic Standing 92

Table 20: Observed Frequencies and Percentages Belonging to a Club or Organization and

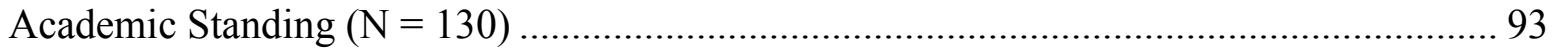

Table 21: Frequencies and Percentages of Counseling Center Utilization................................ 94

Table 22: Frequencies and Percentages of Participants Who Benefited from the Counseling

Center Services

Table 23: Frequencies and Percentages of Counseling Center and Resolution of Problem 95

Table 24: Log-linear Parameter Estimates, Values, and Goodness-of-Fit Index for Utilization of

UDC Student Counseling Services and Academic Standing 96

Table 25: Observed Frequencies and Percentages of Utilization of UDC Student Counseling

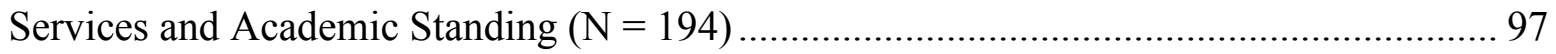

Table 26: Frequencies and Percentages of Academic Advisory Meeting with Advisor ............. 98

Table 27: Frequencies and Percentages on Satisfaction with the Academic Advisory Meeting.. 98 Table 28: Log-linear Parameter Estimates, Values, and Goodness-of-Fit Index for Interaction with Academic Advisors and Academic Standing...... 99

Table 29: Observed Frequencies and Percentages of Interaction with Academic Advisors and

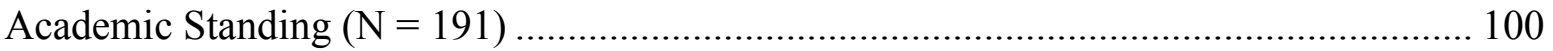

Table 30: Frequencies and Percentages of Academic Standing 100 


\section{Chapter 1: Introduction and Statement of the Problem}

As the city's only public university and the nation's only urban public land-grant institution of higher education, the University of the District of Columbia (UDC) has the responsibility of educating incoming students who, in many instances, are the first generation in their families to attend college. Forty-eight percent of students enrolled for the fall 2009 at UDC were first-generation students. Most of these students are underprepared for college-level study. Of the eight District Wards, 77\% of the total enrollment for the fall 2009 semester and $81 \%$ of the fall 2008 semester were District of Columbia (D.C.) residents. More than half of the D.C. residents enrolled in UDC were undergraduate students (University of the District of Columbia, Office of Institutional Research, Assessment and Planning, 2009).

A U.S. Department of Labor, Bureau of Labor Statistics (2010) report indicated that more than $70.1 \%$ of 2009 high school graduates were enrolled in U.S. colleges or universities. Although many students successfully navigate their initial year in higher education, more than $40 \%$ of those who enroll fail to complete their degree (Mattanah, Ayers, Brand, Brooks, Quimby, \& McNary, 2010).

The District of Columbia public school system (DCPS) has a history of poorly preparing students for college-level study. According to Mabeus (2007), only 9\% of District children who graduated from public high school and enrolled in college graduated from college within five years. For many students, UDC is not their first choice, but for those who desire to attend college in the District and lack the entry requirements, entrance into the university-system of the District of Columbia begins at the newly created community college. This is primarily due to the 
institution's recent separation into a university system consisting of a community college and a flagship university. The community college has retained the previous open admission policy.

UDC is an urban, four-year, public, institution located in Washington, D.C. The university is predominantly a commuter campus. Congress established the university's current configuration in 1977 following the findings of a commission appointed by President John F. Kennedy to study the educational needs of the citizenry of the District of Columbia (University of the District of Columbia, n.d.). Citizens of the District of Columbia desired a comprehensive four-year institution in the nation's capital. Three predecessor institutions, the District of Columbia Teacher's College (1955), Washington Technical Institute (1968), and Federal City College (1968) merged to form UDC. Just as the merger brought together several distinct characteristics, UDC's organizational culture is defined in a number of ways; it is known as the something for everyone institution and as an institution where dreams still come true and students who may begin college ill prepared are provided with the tools to persist should they decide that they are ready for the academic challenge.

Recent studies about remediation indicated that $40 \%$ of all undergraduate students would enroll in at least one developmental course (Attewell, Lavin, Domina, \& Levey, 2006). During the fall 2009 semester, $88 \%$ of all first-time entering students were placed in a minimum of two developmental courses at UDC.

The University System of the District of Columbia serves many populations within the D.C.-metropolitan area, and it offers programs at the certificate, associate, baccalaureate, and master's degree levels. Approximately $70 \%$ of UDC's undergraduate students are from the District of Columbia (University of the District of Columbia, 2009). UDC's long history and development from a school for African-American girls in 1851 to its current configuration has 
served the culture of the university greatly. Being a part of the urban culture that exists in the District requires that the values, mission, and beliefs that are associated with the institution are shared by each population. UDC was founded upon many of the same principles that other historically black colleges and universities (HBCUs) - principles by which an underserved population would become educated. These principles assisted in the formation of the culture that persists to this day at all HBCUs: faith, uplift, perseverance, and excellence (Ashley, Williams, \& Ingrum, 2004).

UDC has a large population of non-traditional students. In the fall of 2009 , the average age of all students, not including the law school, was 27.5 years. The U.S. Department of Education (2002) identifies non-traditional students as having one of several characteristics: delayed enrollment, students beyond the age of 24, attends part time, works full time, financially independent, has dependents other than a spouse, or is a single parent. According to Gilardi and Guglielmetti (2011), much of the research indicated that non-traditional students present a higher risk of dropping out than traditional-age students (18-24 years of age).

The programs offered at UDC respond to the needs of the local and regional communities as well as prepare students for entry into the workforce, their next level of education, and for lifelong learning. The total enrollment at UDC, as of fall 2009, was 5,526 students; $70 \%$ of the students were District residents. The remaining students were from the surrounding metro area and from 101 foreign countries (UDC Office of Institutional Research, Assessment and Planning: Enrollment Profile Report, Fall, 2009).

Against academically challenging odds, what factors influence students to persist beyond their initial year of college at UDC? Is the first-year experience (FYE), as it exists now, making a difference in whether a student returns to college beyond his/her initial semester? Though there 
are inherent concerns characteristic of this urban, non-residential institution, no research has been conducted that analyzes why half of UDC's first-year students persist beyond their initial year.

\section{Purpose of the Study}

The purpose of this study was to investigate whether four selected predictor variables were associated with a student's eligibility to return for the fall 2010 semester in good academic standing which is defined in this study as a 2.0 GPA or higher, at UDC.

\section{Research Questions and Hypotheses}

This study addressed the following questions

1. Is there a relationship between enrollment in the freshman orientation course, during the initial year at UDC, and a student's eligibility to return for the fall 2010 semester in good academic standing?

2. Is there a relationship between belonging to a UDC student clubs, organizations, or athletics and a student's eligibility to return for the fall 2010 semester in good academic standing?

3. Is there a relationship between utilization of UDC student counseling services and a student's eligibility to return for the fall 2010 semester in good academic standing?

4. Is there a relationship between formal meetings with academic advisors and a student's eligibility to return for the fall 2010 semester in good academic standing?

Students of color and those from underserved populations experience some of the lowest retention rates at the UDC. For those students who continue beyond their initial semester or year, there are elements within the academic environment that support them and provide the impetus for them to be eligible to return for the fall 2010 semester in good academic standing. 
Whether a first year student was eligible to return for the fall 2010 semester was measured by reviewing the end of semester grade point averages. If students were in good academic standing, i.e., 2.0 or higher grade point average, they were considered eligible to return, even if other factors, e.g. family or financial issues, prevented them from doing so.

First-year students from underserved communities take longer to accomplish their educational objectives. Though success is not always defined by graduation from college, there are aspects within the institution that assist students in forming a connection to their academic environment. Understanding which aspects of the university environment influence students about their decision to return could provide critical retention information for university staff. According to the Noel-Levitz National Freshman Attitudes Report (2010), firstgeneration students entering college during the fall and summer 2009 semesters indicated that they were determined to complete their degrees. Thirty-one percent indicated that the current economic climate was very distracting and troublesome. Of the 96,641 first-year students who completed the attitudinal survey, the majority of students utilized campus counseling services to help with study habits and to identify part-time employment.

The National Freshman Attitudes Report (2010) student population consisted of $48.1 \%$ students of color: African-Americans (24.3\%), Hispanic/Latino (20.1\%), Multi-Ethnic (2.9\%), and American Indian/Alaskan Native (0.8\%). The report also looked at the education of the students' parents. According to the report, $65.7 \%$ of first-generation students reported that the highest educational level completed by their mothers was high school, and $63 \%$ reported that their fathers' highest educational level was high school. A study conducted by Martinez, Sher, Krull, and Wood (2009) suggested that "low parental education was a risk for attrition" (p. 2). According to the report, $40.5 \%$ of the first-generation students plan to complete a bachelor's 
degree, and 25.2\% plan to complete a master's degree (National Freshman Attitudes Report, 2010). Given the overall academic environment, the experiences, and support that students bring with them to college during the first year, it seems logical that institutions of higher education would capitalize upon the survey information that they gather from students, and seriously put the information to use toward more successful retention programming where it is in fact needed.

Researchers such as Pascarella (1984), Terenzini (1987a, 1987b, 1996), and Tinto (1975, 1993, 1996), have examined college environments throughout the U.S. They have explored the advising and counseling aspects of the college environment as well as how students engage with faculty, with one another, and how certain integrated programs such as the freshman orientation course combine both academic and student affairs perspectives. What they have found is that although there is no standard for creating an environment of student success, there are key elements involved in the creation of an environment for first-year students no matter the institutional type.

Tinto (1993), in his student integration model, emphasized the importance of student engagement in the social and academic aspects of the institution. The University of the District of Columbia, First-Time Entering Freshman Retention Profile Report (2009), indicated that $50.6 \%$ of those students who began college during the fall 2008 returned for the fall 2009 semester. In the fall $2009,36 \%$ of UDC's first-time entering students were African-American, and $67.4 \%$ of first-time entering students were from the District of Columbia.

Overall, research is limited with regard to how minority students experience their first year. The assumption for the scarcity of minority-related research is that many researchers believe that race and cultural identity are of no significance in the overall development of students (Pope, 1998). According to Pope (1998), the various models and theories of college 
student development failed to consider the culture-specific aspects of development. They assumed that all students experienced developmental phenomena the same way. For instance, Arthur Chickering, through his Theory of Identity Development $(1969,1994)$, proposed seven vectors by which students developed. This initial theory was created absent of information on how minority students experience college within a different set of cultural norms.

The student development theories that were created over 40 years ago disregarded the developmental factors, racial identity, and cultural nuances of minority students (Pope, 1998). Most college development theories assumed that growth occurs in a single language/culture environment, and more importantly, these theories adhered to a system that encompassed those values held important by the majority population. Each of the factors indicated above may influence the worth and quality of the education that students receive. The areas emphasized above, when integrated into a comprehensive first-year experience, may also better prepare students to persist and remain enrolled through completion of their program of study.

As mentioned previously, success is defined differently depending on the student; it is not always defined by degree attainment and academic ambitions. Student success may be defined by some students as the transition from high school to college and getting involved in a student organization; others may define it as moving beyond remedial coursework and developing new competencies. Therefore, it must be carefully noted that the focus of this study was not to determine who would physically return for the fall 2010 semester or if they would reach degree attainment, but who would be eligible to return for the fall 2010 semester.

Currently, no research exists which addresses the variables indicated in this study as they relate to the semester-to-semester persistence rates of UDC students. This study utilized data obtained from a researcher-constructed, 23-item pilot survey. This survey was designed to 
obtain responses from first-year students concerning their involvement with each of the four variables being examined in this study. The survey was administered to 200 students enrolled in the following courses: English, Reading Improvement, Basic Math, and Introduction to Algebra. Seven 100-level courses were chosen that consisted of English Composition I and II, General College Math I and II, Intermediate Algebra, Psychology, and Public Speaking.

\section{Hypothesis}

The hypothesis of this study is that the elements of the first-year experience, chosen for examination, were associated with a first-year student's eligibility to return fall semester 2010 in good academic standing.

\section{Null Hypotheses}

The following null hypotheses were tested:

HO1: There is no significant relationship between enrollment in the freshman orientation course, during the initial year at UDC, and a student's eligibility to return for the fall 2010 semester in good academic standing.

HO2: There is no significant relationship between belonging to UDC student clubs, athletics, or organizations and persistence to the fall 2010 semester in good academic standing.

HO3: There is no significant relationship between student utilization of UDC student counseling services and persistence to fall 2010 semester in good academic standing.

HO4: There is no significant relationship between student interaction with academic advisors and persistence to fall 2010 semester in good academic standing.

Not unlike many traditional students, the first year for many minority students requires acclimation to a major life transition; it requires adjusting to an unfamiliar environment, 
establishing relationships with new people, and redefining relationships with high school friends and family (Upcraft, Gardner, Barefoot, \& Associates, 2005).

A marked challenge for many minority students is adopting new roles and leaving old roles behind. Students who choose to attend college bring with them a value system supported by the values of their parents and loved ones. Once engaged in their first year, students find that their old ways of thinking and their beliefs will be challenged, and they begin the process of reevaluating their value and belief systems in an attempt to find their own voice and significance (Twigg, 2005). This is true of students who come from very homogeneous environments and are at once thrust into an environment that, by contrast, is very diverse and lacks the homogeneous nature of their hometown. For many students, the differences in the new university environment outweigh the benefits of remaining, and unfortunately many students succumb to the stress and pressure of the transition and they fail to complete their first year. The National Center for Education Statistics (as cited in Upcraft \& Schuh, 2001) stated,

Twenty-four point four percent of students who began their postsecondary education by enrolling at a four-year institution in 1989 were no longer enrolled in 1994 and had not earned a degree, and dropout rates at institutions that enroll nontraditional students are even higher. (p. 213)

The Noel-Levitz National Freshman Attitudes Report (2010) stressed that in order to address the retention question, institutions must first have a better understanding of their student profile and identify high-priority sub groups, as these different cohorts bring an entirely different set of attitudes to the academic setting. It also suggested that identifying significant barriers and opportunities would assist in adapting programming and services so that student satisfaction 
increases. Understanding attitudes may result increase persistence and should be a central focus of all student retention programs.

The attrition trend has not changed much. According to Twigg (2005), "an estimated 60 percent of students at public institutions fail to complete degrees within five years, and half of these students leave during the freshman year" (p. 2). The ACT Institutional Data File (2008) indicated that the national freshman-to-sophomore retention rate for open admission four-year public institutions (offering both Bachelor's and Master's) was 65.7\%. This figure has significant implications for the curriculum and learning outcomes at UDC where the entering freshman cohort consists predominantly of minority students, the majority of whom are deficient in basic academic skills. Typically, students who do not have the skills to negotiate the academic demands of college will drop out of school during their first year.

While the number of students retained from fall to fall semester from 2005 to 2009 at UDC increased each year, the percentage of students who were retained for each of the five semesters remained below the national average of $65.7 \%$. Fall semester 2009 experienced the greatest retention rate of all five years as $50.6 \%$ of first-time freshman were eligible to return for the fall 2009 semester. Table 1 includes the entering freshman cohorts and their retention rates from fall 2005 to fall 2009. 
Table 1

First-to-Second-Year Retention of UDC Students 2005-2009 (Part-Time/Full-Time)

\begin{tabular}{cccc}
\hline Cohort Year & $\begin{array}{c}\text { First-Time Freshmen } \\
\text { Enrolled }\end{array}$ & $\begin{array}{c}\text { Freshmen Enrolled } \\
\text { Second Year }\end{array}$ & $\begin{array}{c}\text { First to Second Year } \\
\text { Retention Rate }\end{array}$ \\
\hline Fall 2005 & 783 & 320 & $40.9 \%$ \\
Fall 2006 & 695 & 291 & $41.9 \%$ \\
Fall 2007 & 825 & 355 & $43.0 \%$ \\
Fall 2008 & 679 & 325 & $47.9 \%$ \\
Fall 2009 & 940 & 476 & $50.6 \%$ \\
\hline
\end{tabular}

Note. Source: University of the District of Columbia Office of Institutional Research Assessment and Planning. First-Time Entering Freshmen Retention Profile Report (2002-2009) and Office of Institutional Research, Assessment and Planning: OIT Frozen Data Dump (Spring 2011).

As reported by the Office of Institutional Research, on average, more than half of the students who enrolled as freshmen during the period fall 2005 through fall 2009 were required to enroll in a minimum of two developmental courses based upon results of the ACCUPLACER (placement) test scores.

On many public commuter campuses, student involvement has become a minor part of the college student experience, and student demographics have altered what was traditionally an integral part of the college experience. The majority of the population tends to be non-traditional students who are managing full- and part-time employment. These students have little time to devote to on-campus activities, meetings with faculty members, and other aspects of what has been uniquely a college experience (Barefoot, 2004).

The non-traditional student population grew most noticeably following the passage of the Servicemen's Readjustment Act (GI Bill) of 1944. Military men and women beyond the 
traditional college age of 18 to 24 have taken advantage of the educational benefits that this bill provides after their return to civilian life. Many other students today enroll in on-line courses for convenience and in order to save time. According to Tinto (1993),

It is not surprising to find that persons who typically enroll for more limited and very specific educational ends are somewhat older than the typical college entrant and more often enrolled on a part-time basis and/or holding a job while attending college. (p. 39) A significant percentage of these students have parental responsibilities as well. For these reasons, as well as many others, it is very difficult to get and keep students involved in campus programs and/or activities during the evenings and on weekends.

Because of a lack of involvement in campus activities and initiatives, students fail to benefit from student-to-student interaction as well as the developmental components of what the first-year is thought to encompass. A growing body of research demonstrates that there is a direct correlation between student-faculty and student-to-student interaction and retention (Pascarella \& Terenzini, 1991). Many minority students entering UDC lack the skills necessary to navigate their initial semester of higher education and typically do not return the following year, if they complete their second semester.

The freshman orientation course is not a mandatory course for all first-year students at UDC. Despite on-going efforts to enhance both academic advising and increase the number of students who are enrolled in the freshman orientation course, there are several faculty members who do not support these efforts and who have not recognized the importance of a comprehensive and well implemented transitional course and its impact upon first-generation students. This study seeks to prove that a comprehensive and inclusive first-year experience is critical to raising retention rates of UDC's first-year students. 


\section{Assumptions}

The underlying assumptions for this study are that each of the four predictor variables (student enrollment in a freshman orientation course; academic advising; utilization of student counseling services; and student participation in University clubs, athletics, and organizations), are associated with a student's eligibility to return for the fall 2010 semester in good academic standing at UDC.

\section{Definitions of Key Terms}

Academic environment The academic environment is comprised of the academic and social dimensions of higher education; where the academic and social attributes of college life merge with student development.

First-year experience (FYE) FYE is an intentional approach by the institution to combine the curricular and co-curricular programming and services offered by the university.

Freshmen orientation course The freshman orientation course is a transition course for first-year students. While many first-year students enroll in this course, it is currently not a mandatory course for first-year students at the University of the District of Columbia

Good academic standing Good academic standing is defined as having a grade point average of 2.0 or higher, at the end of an academic semester.

Historically black colleges and universities (HBCU) HBCU institutions are those institutions of higher education that were founded prior to 1964 that, then and now, share a common mission to meet the educational needs of Black students and prepare students for leadership and service roles within the larger community. 
Persistence Persistence was defined in this study as the ability of those students who begin their freshmen year during the fall 2009 or spring 2010 semester to be eligible to return for the fall 2010 semester in good academic standing (i.e., 2.0 GPA).

Student counseling center The student counseling center is dedicated to assisting students with anxiety, depression, academic issues, and other concerns that may impede academic and developmental growth or cause a student to depart from the institution.

Student success Student success, for the purposes of this study, is defined as the ability of the student to return for the fall 2010 semester with a 2.0 or higher. Students should not have been placed on academic probation, and barring any financial or familial concerns, would have returned to the institution.

Undeclared majors Undeclared major is a term that designates students who enroll at UDC who are undecided about the course of study that they will pursue.

\section{Significance of This Study}

This study is significant because it draws attention to the reasons why some students persist beyond their initial year of college at UDC, and it may have implications for other institutions of similar characteristics. UDC is atypical because it is an urban institution that has the responsibility of serving multiple publics. UDC is a predominantly non-residential campus, and it has a large concentration of part-time and non-traditional students. There is a need for the administration, faculty, and staff to better understand and collaborate in the enhancement and creation of improved retention initiatives, especially during the first year. By implementing the best practices involved in retention, the institution retains more of its students and increases the annual graduation rate. Results from this study will be used to help UDC faculty and administrators better prepare students to persist and remain enrolled through completion of their 
program of study. Similar public urban institutions like UDC may also benefit from the findings and be able to make more informed decisions on how best to serve under-prepared students as they enroll in college for the first time and how to identify what elements are important to have in the surrounding academic environment.

\section{Organization of Dissertation}

Chapter one addressed the retention scenario at the University of the District of Columbia. Chapter one also established the context of student retention at UDC, the challenges of first-generation and entering freshman students. It also focuses on the lack of research that exists with regard to first-generation and students of color entering college for the first time.

Chapter two, the literature review, is comprised of four sections. The first section establishes a framework of retention studies conducted with relation to the importance of the freshman orientation course; the second section is a discussion of major bodies of research that focus on student involvement and its role in student success; the third section reviews the literature concerning national counseling trends and underrepresented students, and the fourth section explores the literature with regard to the role that academic advising plays in the retention of first-year students.

Chapter three addressed the research design of this study, the population, a description of the instrument, as well as data collection procedures, and the statistical analyses that were used. Chapter four addressed the frequencies and percentages of the demographic data as well as each of the four research questions in detail. There are three tables presented for each research question: a table of frequencies and percentages, loglinear parameter estimates, and frequencies and percentages with regard to academic standing. Chapter five discussed summary of findings, conclusions, recommendations for practice, and recommendations for future research each of the 
four independent variables and the results of the null hypotheses, findings and recommendations for practice and future research, and limitations of the study. 


\section{Chapter 2: Review of the Literature}

\section{Freshman Orientation Course}

Freshman orientation is one of the most researched curricular innovations of our time. In many cases, the freshman orientation is the anchor of the first-year experience. This course, in varied formats, serves students from an array of backgrounds, ethnic groups, races, and socioeconomic status. The influence of this single course has assisted students in persisting in college and attaining their academic goals. All students have a first-year experience, whether it is the intent of the university or not (Hunter, Henscheid, \& Mouton, 2007). It has become necessary for most institutions to create unique engagement opportunities for students from varying backgrounds.

For many students, the freshman orientation course serves as a transition course from high school to college, it also assists students to engage in their initial year of college. According to the National Survey of Student Engagement (NSSE) (2008), "some students have built high expectations for their collegiate experience based on the stories of family, friends, teachers, while others have not" (p. 17). These students may enter college with enhanced expectations about social integration and the college environment itself.

It is important to include in this discussion the plight of many first-generation students because transitional concerns and attrition affect this population so dramatically. Martinez, Sher, Krull, and Wood (2009) suggested that first-generation students entering college might be very unfamiliar with college life and expectations, and therefore be at a disadvantage for their initial year. Ishitani (2006) suggested that students who have college-educated parents are more likely to complete their college education than first-generation students. Second and third generation students begin college with parents and siblings who have passed on knowledge and other 
important information regarding institutional expectations; this may ease their transition from high school to college; these students may also be perceived as more college ready. Students who have college-educated support systems may experience transitional issues differently than first-generation students who lack similar support systems; first-generation students may find much needed assistance in the freshman orientation course. The NSSE Annual Report (2008) suggested that "institutions need to find ways to not only increase, but also sustain engagement with different populations" (p. 17). Information about the first-year experience that firstgeneration students are missing may be enhanced during the course as it serves as a gateway to a new environment and introduces them to the purpose and meaning of participation in a very important stage in their lives (Cuseo, n.d.).

The roots of the first freshman orientation course can be traced to the $19^{\text {th }}$ century; its contemporary is now found on more campuses than not in the United States (Gordon, 1989). Today, many researchers and advocates acknowledge that the freshman orientation course, in some form or another, is relevant and critical for student success. Though the idea of the freshman orientation has been around for over a century, the research that documents the successful outcomes of this course has not been absolutely conclusive with regard to the particular elements of freshman orientation that influence student success (Goodman \& Pascarella, 2006). This section of the literature review will review the history, characteristics of the freshman orientation, as well as future trends of this ubiquitous first-year initiative.

\section{Origins of the First-Year Orientation and its Contemporary Structure}

The origins of the freshman orientation course began in 1877 with the formation of a faculty advisor system at Johns Hopkins University (Gordon, 1989). Similarly at Harvard University, a board of first-year student advisors was created in 1889 (Gordon, 1989). The 
recognition that new students arrive to college with an assortment of different needs and expectations, prompted many institutions (e.g., Boston University, the University of Michigan, and Oberlin College) to offer students orientation courses that were not factored into their degree programs to assist with their transition from secondary school to college (Gordon, 1989). It was in 1911 at Reed College that the first freshman orientation course was offered for credit (Gordon, 1989). By the middle of the 20th century, $43 \%$ of all institutions of higher education included a required orientation class (Gordon, 1989).

Tobolowsky, Mamrick, and Cox (2005), found that over $80 \%$ of institutions in the U.S. offered a freshman orientation course in various formats. The freshman orientation has received increased validation from faculty, more emphasis from campus administrations, and includes more traditional academic content than previously (Tobolowsky et al., 2005). More faculty members now view this course as a valid curriculum innovation (Tobolowsky et al., 2005). A change in terminology by numerous institutions from freshman orientation to first-year seminar has been accepted, and many institutions have found a new respect for freshman orientation, as there has been an apparent increase in the academic rigor of the course (Hunter \& Linder, 2005).

Pascarella and Terenzini (1991), in their text, How College Affects Students, focused on the needs of new students during their initial year in college as well as the programs that were developed by institutions to increase persistence. In 2005, Pascarella and Terenzini revisited their initial research with new information that focused on and synthesized the numerous retention studies that had been developed since the initial text in 1991; the researchers found that since the 1980 s, retention research had multiplied.

Researchers from the University of South Carolina-Columbia indicated that those students who were enrolled in freshman orientation between 1973 and 1996 were more likely to 
return for the fall semester of their sophomore year than those students who did not participate in the freshman orientation. The researchers also found that there was evidence that pointed to an increase in student persistence as well as an increase in the varieties of freshman orientation that exist throughout higher education in the U.S. (Goodman \& Pascarella, 2006). Goodman and Pascarella (2006) stated that "the common goal of first-year seminars is to increase academic performance and persistence through academic and social integration; the long-term goal is increased degree attainment” (p. 26). During the 23 years between 1973 and 1996, the University of South Carolina-Columbia researchers found that the differences in students who participated in freshman orientation versus those students who did not were statistically significant for 15 of the 23 years.

Pascarella and Terenzini (2005) synthesized 40 retention studies and found that students who participated in freshman orientation were also more likely to graduate in four years as opposed to their classmates who did not participate in freshman orientation. In their initial body of research, Pascarella and Terenzini (1991) concluded, "the weight of the evidence suggests that a first-semester seminar is positively linked with both freshman-year persistence and degree completion. This positive link persists even when academic aptitude and secondary school achievement are taken into account” (pp. 419-420).

The University of Maryland-College Park (UMCP) study was included in Pascarella and Terenzini's (2005) later research. UMCP used a true experimental design to explore the impact of seminar enrollment for four semesters. The findings in this study confirmed that those students enrolled in freshman orientation were more likely to persist than those students who did not participate in freshman orientation (Goodman \& Pascarella, 2006). 
The evidence for the support of freshman orientation is abundant and has expanded over the years, but researchers continue seeking the causal link between freshman orientation and desirable outcomes related to persistence. Goodman and Pascarella (2006) suggested that longitudinal studies are the best ways to find the aspects of the freshman orientation that positively link this course to student persistence. The researchers believed that employing the use of longitudinal studies allows for the control of precollege characteristics such as high school grades, socioeconomic status, and other factors that may confuse the actual relationship between freshman orientation participation and student persistence.

\section{Rationale for the Existence of the Freshman Orientation Course}

Freshman orientation courses are called by many names and serve several purposes depending upon the institution. Freshman orientation, student success course, and first-year seminar are just a few of the names given to an all inclusive course that serves to assist first-year students with their academic and social integration into college.

As previously suggested, the purpose or nature of the freshman orientation course will vary depending upon the institution. These courses bring students together several times a week or semester. Students are encouraged to participate and become integrated in the class. Unlike other first-year courses, the freshman orientation recognizes students for their individual characteristics and participation (Barefoot, 1998).

A missing element in the research is to find which students best benefit from freshman orientation programs. Because freshman orientation courses are offered in such a wide array of formats and serve as an all-purpose intervention on many campuses, the evidence supports freshman orientation as beneficial for all types of students no matter the demographics (Goodman \& Pascarella, 2006). In many instances, freshman orientation has proven to go 
beyond the originally intended goals of the course. Retention research reveals that students who participate in freshman orientation enjoy more interaction with other students and faculty; they are more involved in activities outside of the classroom; their grades are higher, and more students indicate that their satisfaction level is increased with regard to their overall college experience (Goodman \& Pascarella, 2006). Retention models proposed by Pascarella and Terenzini (1991), Spady (1971), and Tinto (1975) previewed background characteristics as a component in theoretical persistence and retention. Ishitani (2006) suggested that each of these models emphasizes the importance of interaction between students and their environments in the decision to depart college.

\section{Course Objectives and Varied Content Freshman Orientation Courses}

There are three overall aims of the freshman orientation, which are to (a) assist students in their academics, (b) assist students with social development, and (c) assist students in their transition to college-both in their academic and social development. For many students, the freshman orientation can be the foundation upon which the first-year experience is grounded. The first-year design that an institution uses should be such that it complements the identity of the institution, i.e., the campus profile, student population, etc. The use of an advisory board to monitor programs as well as to institute vital changes is highly recommended. The inclusion of students on the advisory board as well as the entire program is also advisable. Programs should include as many campus resources in the learning design of the course as possible (Clark, 2005).

\section{Varied Types of Freshman Orientation Courses}

According to Porter and Swing (2006), the difficulty in identifying the particular aspects of the freshman orientation course that influence student persistence is lacking because much of the existing research is based on single-institution studies and the overall impact of the freshman 
orientation course rather than particular elements of the course. One way of increasing success and persistence is to identify student strengths and increase their participation in engaging activities that affect their academic growth and development.

The types of freshman orientation courses are varied and can be quite specific to particular colleges or universities. Porter and Swing (2006) separated the freshman orientation programs into seminar types. Eighty percent of the colleges surveyed offer letter grades for the freshman orientation course and are receiving more validation from faculty as well as more emphasis from campus administrations (Porter \& Swing, 2006). Extended orientation programs have become quite prominent. Sixty-two percent of colleges and universities surveyed by Porter and Swing (2006) offered an extended orientation through the first year; many freshman orientation courses emphasize academic skills and campus resources and skills development. Freshman orientation courses that focus on basic study skills and those that are geared toward specific programs of study have also become prominent (Henscheid, n.d; Upcraft et al., 2005).

Barefoot (2004) explored how elements within the environment determine persistence of first-year students. The studies of Barefoot (2004) and Porter and Swing (2006) similarly attempted to understand how aspects of the freshman orientation affect early intentions to persist instead of the impact of the overall course. Other researchers have also examined the institutional environments that will most likely correlate with higher rates of persistence (Astin, 1991; Pascarella \& Terenzini, 1991).

It is not just that freshman orientations are taught-it is important that freshman orientation courses be engaging and involve effective and engaging pedagogy. Self-assessment should be of primary importance in first-year student orientation programs and first-year seminar courses. According to Swing (2003), "challenging assignments, meaningful homework, and 
productive classroom time are associated with greater learning outcomes" (n. p.). Results from the 2001 First-Year Initiative survey reflected that learning outcomes and student satisfaction with the first-year seminar were highly correlated with the way teachers conduct first-year seminars (Porter \& Swing, 2006).

Within the context of establishing a focal point for which aspects of the freshman orientation influence student persistence, Mammary (2003) designed a gender-specific freshman orientation at a small liberal northeastern college in the U.S. The creator of this freshman orientation sought to change the impact that the college environment, or its culture, had on firstyear women who were enrolled in the particular course. Her goal was to rid this particular freshman orientation section of the typical sexist and racist ideologies that were embedded in the culture, language, and communication of this college environment.

Forty-seven women from diverse backgrounds and classes participated in this course. The main intent of the course was to give women in the dominant and minority groups a voice. In order to examine all aspects of this course, a faculty retreat was arranged to address perceptions of race and gender on campus from the faculty perspective. There is a perception that an equitable coexistence becomes a problem for women and minorities when they do not feel as if they are able to effectively contribute and participate in their environment. Freshman orientation literature suggests that freshman orientation courses designed for specific populations strengthen students' awareness and character and lead to persistence (Mammary, 2003).

\section{The First-Generation Student}

For incoming freshmen, college is a new world full of challenges, obstacles, opportunities, and constant change. This new world requires the students' negotiation of challenges in their academic world, new friends, professors, and people external to their 
academic world (Clark, 2005). The NSSE Annual Report (2008) addressed the plight of firstgeneration students. The report indicated, "the overrepresentation of first-generation students within the underprepared population signals that these students might have limited relevant experiences to support their transition to college" (p. 19). More minority students are entering college today than they historically have. However, fewer minority students earn degrees in six years, unlike their non-minority counterparts who earn their degrees in five years or less.

The reasons why students leave school are varied and include, but are not limited to, program of study, financial difficulties, family concerns and demands, poor psycho-social fit, etc. (Braxton, 2000; Braxton, Hirschy, \& McClendon, 2004; Kuh, Kinzie, Buckley, Bridges, \& Hayek, 2007). Ishitani (2006) suggested that other variables that are significantly associated with departure include "family income, lower educational expectations, lower high school class rank quintile, lower high school academic intensity, enrollment in a public institution, and enrollment in non-selective institutions" (p. 872).

Much more consideration is necessary to respond to why first-generation students show higher risks of departing college during years one through four, than second- and thirdgeneration college students. Of the students enrolled in their first year of college at four-year institutions in 1995-96, only 5\% completed bachelor's degrees within six years at their first institution (Kuh, Cruce, Shoup, Kinzie, \& Goyea, 2008). Degree completion rates are much lower for students from underserved populations (Kuh et al., 2008). Student success is multidimensional; the reasons why students start college and continue and which factors interact in their individual experiences vary significantly. According to Twigg (2005),

NCES data indicate that one-quarter of freshmen are from low-income backgrounds, almost one-third are nonwhite, and 40 percent are the first in their families to attend 
college. Such students-often not as academically or socially prepared as others for higher education-are more prone to drop out. Indeed, 45 percent of African-American students and 39 percent of Hispanic students, on average, leave four-year institutions within six years without earning degrees, compared with 33 percent of white students and 26 percent of Asian-American students. Similar gaps exist by income: students from lower income backgrounds are significantly less likely than students from higher-income backgrounds to go on to earn bachelor's degrees. Although many students, who do not may have met other personal goals, both educators and policy makers consider these rates to be too low. (p. 1)

Braxton et al. (2004) suggested that a better understanding of why underrepresented students depart school and how they experience college is a very little known part of retention literature. Many aspects of student retention research examine student success by: (a) student background and demographics/pre-college; (b) institutional size, mission, and selectivity; (c) faculty, peers, and staff interactions; (d) student perception of the academic environment; and (e) quality of effort that students expend to educationally purposeful activities. What the literature lacks is a better understanding of how these aspects of college affect minority and firstgeneration students, many of whom tend to be students from underserved populations (Braxton et al., 2004). The aforementioned aspects of success are each elements of the college experience that minority students experience differently from White students at predominantly White institutions (PWIs). Pascarella and Terenzini (2005) suggested that the study of the minority student college experience warrants more attention. Few studies on this topic include empirical results from multi-institutional data. 


\section{Evidence of First-Year Experience Effectiveness}

Research is limited with regard to the impact of various aspects of the freshman orientation (Barefoot, 2004; Porter \& Swing, 2006). The First Year Initiative Benchmarking Survey (2002) reflected that students are receptive to assistance when they first arrive. The previous experiences of beginning college students during the first three to six weeks of college have been found to assist them in the decision to depart school (Barefoot, 2004).

Barefoot (2004) and Porter and Swing (2006) sought to understand how various aspects of first-year seminars influence student intentions to persist. The specific content areas of freshman orientation that the researchers were interested in were those that indicated a greater intent to persist among first-year students. Barefoot (2004) examined how specific elements of the freshman orientation determine persistence. More specifically, she examined the environment-the academic and social dimensions of higher education and how these two elements must be acknowledged when grappling with the student retention puzzle. Barefoot (2004) utilized Tinto’s (1993) retention model as a framework for her research. Tinto (1993) explored retention as a three-stage process resulting in varying degrees of academic and social integration; his model is the foremost theoretical perspective on retention. Barefoot (2004) suggested that those aspects of the college experience, i.e., academic course sequencing, attendance policies, academic advising, rewards, and selection of faculty assigned to first-year students should also be examined because of the impact these structures may have in the retention of students.

\section{Lessons Learned from the First-Year Experience at the University of Texas at El Paso}

What does an institution do about students who arrive on its campus from low socioeconomic backgrounds who are academically under prepared? How is an institution 
successful in encouraging students to continue their education? Which innovations are at the institution's disposal? What impediments, if any, are presented by the university as students continue through school? Former First Lady Lady Bird Johnson once said, "children are apt to live up to what you believe of them." The same can be said of young students; if students harbor negative beliefs instilled in them by their parents and other significant people in their lives, the nation would miss out on the talents and skills of countless capable students.

The University of Texas at El Paso (UTEP) took into consideration each of the variables that may present challenges to its specific population, i.e., historically under represented students, family responsibilities, socio economic status, etc. Taking these variables into consideration allowed the institution to shape its response to its retention concerns. UTEP decided to focus on entering first-year students in order to prepare them for success; what many of these students experience before coming to the college campus goes beyond the ordinary transitional challenges of other first-year students. UTEP decided that an environment would be created for this group that would be nurturing and at the same time challenging as these students worked through the transition process (Natalicio \& Smith, 2005).

The UTEP experience included welcoming, supportive, and intellectually stimulating course content (Natalicio \& Smith, 2005). The first-year experience at UTEP was comprised of structured academic and social opportunities from which student "learning is enhanced and their sense of community is defined" (Natalicio \& Smith, 2005, p. 163). UTEP realized that a critical part of student success was also faculty perception toward students who may have markedly difficult values, expectations, and attitudes from themselves (Natalicio \& Smith, 2005). Several workshops were designed to assist faculty in developing sensitivity toward these differences; this 
contributed to a better understanding of the student body as well as supported the overall retention goals of the institution (Natalicio \& Smith, 2005).

UTEP formed an FYE task force composed of student leaders, first-year leaders, faculty, decision makers, FYE enthusiasts, and naysayers to plan the upcoming year as well as to investigate the high rate of student drop out during the initial year. The objectives of the task force were specifically to determine what the components of the UTEP FYE would encompass, the role of the freshman orientation, which academic support services would play an integral role in the FYE, and more importantly, how administrative and organizational functions would collaborate to promote a unified student-centered program for first-year students (Natalicio \& Smith, 2005).

The task force met over the course of the semester and reported its findings to the UTEP president nine months later. The president communicated the importance of the task force's findings to the university community. The president was on-board and announced in an institution-wide memo the formation of UTEP's Entering Student Program (ESP). Because of the importance and academic nature of this program, the ESP was situated within Academic Affairs; it was thought that the ESP would enhance the academic performance of its first-year students. Each of the student development areas that touch students during their first year was placed in the ESP program, i.e., Undergraduate Recruitment, New Student Orientation, Academic Advising, University Studies (freshman orientation), and the Tutoring and Learning Center (Natalicio \& Smith, 2005).

As Barefoot (2004) indicated in her research of the academic environment for first-year students, the environment that students enter into may have a great deal to do with whether students persist or drop out during their initial year of college. UTEP, an institution with a 
student body demographic profile much like UDC, concluded that test scores and four-year graduation rates are not accurate indictors for the majority of first-generation minority students (Natalicio \& Smith, 2005). The six-year graduation rate was $25 \%$, and entering test scores were below the national SAT/ACT averages. Although the urban public institution may not hold the prestige associated with private liberal arts colleges or that of large research institutions, UTEP students are able to compete with other graduates from all over the country with varied backgrounds despite their entrance exam scores and graduation rankings. The UTEP mission provides for access as well as comprehensive institutional support of its first-year students that ensures that they have every opportunity to succeed.

\section{The First-Year Initiative Survey}

Similar to the restructuring of the UTEP FYE Program, Porter and Swing (2006) used a multilevel modeling approach to survey 20,000 first-year students at 45 four-year institutions to understand how aspects of freshman orientation affect early intentions to persist-instead of the impact of the overall freshman orientation course. The researchers chose this particular methodology in order to gather information that was more efficient when measuring for course effectiveness. The First-Year Initiative (FYI) survey results indicated that students with better grades and females were more likely to express the intent to return to school, and those students who worked more hours during the week were less likely to express their intent to return (Natalicio \& Smith, 2005). The study also revealed that selectivity of the institution or resources was significantly related to a student's intent to return. The results of this study indicated that health matters and emphasis on study skills were the two main areas of concern for first-year students and that a student's ability to choose freshman orientation content may make a difference in a student's intent to return to school. 


\section{Student Involvement}

Why is involvement during the first year so important? A large body of freshman orientation research suggests that the best indicator of student academic success is the student's academic preparation and motivation (Kuh, 2005). The role of the university has changed in that faculty and administrators must educate an ever-increasing diverse population of undergraduates (Kuh, 2005).

Student involvement in the 21 st-century university entails more than those activities historically limited to classroom interaction; it requires a relationship between the environment and the participant. Researchers have suggested that although it is important for students to participate and take an interest in what is provided in their immediate environment, it is equally important that the role of the institution adapts to student needs (Pascarella \& Terenzini, 2005; Schuetz, 2008). According to Deil-Amen (2011), "students choose to persist when they perceive intellectual and social congruence, or a normative fit between the student and the values, social rules, and academic quality of the college community" (p. 55).

The campus's insistence on involvement implies that there is a responsibility between the student and the university. Astin (1991) suggested that this environment consists of programs, personnel, curricula, and teaching practices as well as the facilities and social and institutional climates that encourage student participation and development. Being an engaged student means reaping the benefits of the academic environment in its entirety (Astin, 1991). The academic environment also includes the social, cultural, and civic dimensions of the educational experiences of students (Kuh, Gonyea, \&Palmer, n.d.). The responsiveness of the institutional environment influences student retention, and in response, the quality of effort expended on social activities by students heightens the college experience and makes it unique for each 
student (Kuh, Gonyea, \&Palmer, n.d.). With regard to the joint partnership required for involvement to lead to success, Pascarella and Terenzini (2005) stated, "since individual effort in engagement is the critical determinant of the impact of college, it is important to focus on the ways in which an institution can shape its academic, interpersonal, and extracurricular offerings to encourage students engagement" (p. 602).

The co-curricular aspect of college life is a meaningful element of the college experience in America. Whether students reside on campus or attend a commuter college, the benefits of engaging in out-of-class activities, clubs, on-campus employment, and student organizations enrich and influence the "quality of student learning and their overall educational experience" (Pascarella as cited in Kuh et al., 2008, p. 2). Commuter students constitute a very diverse population of students who are both traditional and non-traditional in age. They have diverse backgrounds and have complex goals and objectives that are specific to each of their unique situations. Concern about engaging this population has remained because of the number of external influences that demand the time and attention of these students; special attention by student affairs professionals must be placed on student programming needs.

The literature suggests that the further away from campus a student lives, the less likely they are to be involved in programs, groups, and organizations given their family and workrelated responsibilities. Evidence from the NSSE (2008) showed that commuter students spent more than 20 hours per week working off campus, and they also spent less time interacting with faculty and taking advantage of co-curricular activities available on their campuses. Only about half of first-generation students and seniors participated in any co-curricular activities.

This information is important for student affairs practitioners in responding to the concerns of programming and service delivery for this population. Involvement can be a 
strategy that students use to persist and achieve success; the success of first-year students is the responsibility of both the students and the institution. Twenty percent of African Americans and $12.5 \%$ of Hispanic Americans do not persist in four-year colleges beyond the first year (Bridges, Cambridge, Kuh, \& Leegwater, 2005).

Tinto's Theory of Academic Integration Tinto (1993) is one of the foremost theorists to address the relationship between academic integration and early withdrawal (attrition). The importance of students engaging with their environment cannot be overestimated. Tinto's (1993) theory asserted that in order for students to progress, they must integrate and become part of the academic environment. Student involvement is all about the student experience and how students experience college, what they find intriguing, and what captures their attention and provides them with meaningful experiences while making the journey. The journey thus becomes introspective and provides students with the self evaluation needed to either continue the journey or stop where they are. The next section will review current literature associated with student involvement with an emphasis on involvement at minority-serving institutions.

\section{Minority-Serving Institutions (MSIs)}

Many types of minority-serving institutions (MSIs) exist. The literature indicates that MSIs, more so than their PWI counterparts, are better agents of assisting historically underserved populations in succeeding in higher education. Although they are not known to have the most recent technologies or infrastructure, MSIs are nurturing learning environments for underrepresented populations (Fleming, 1984). Students experience less discrimination and their success is valued by the greater whole of the academic community (Flowers \&Pascarella, 1996). MSIs include historically black colleges and universities (HBCUs), tribal colleges and universities (TCUs), and Hispanic serving institutions (HSIs). In support of HBCUs, Fleming 
(1984), Desousa and Kuh (1996), and Flowers and Pascarella (1999) found that these institutions were more successful in including students and immersing them in the academic environment than were PWIs.

Fleming (1984) expounded upon the attributes of HBCUs in her study, and she found that the strength of HBCUs lay in their effectiveness to develop the skills Black students would require as they moved into larger society after college. Brown and Lane (2003) also found similar success relationships between American Indian students and their academic environment in predominantly TCUs. According to Bridges et al. (2005), no studies have been completed that indicate if the same is true for HSIs.

Assessing the Academic Environment Much of the first-year experience research focuses on the first college year and its correlation to desired student learning outcomes. Understanding how students engage in learning can prove useful to institutions seeking to enhance the quality of university education. Some institutions in the U.S. have designed awardwinning first-year programs, whereas other schools struggle to retain students and create a positive learning environment. Because the first year of college has the potential to affect many aspects of a student's life, it is necessary to gain a better perspective of the personal growth and development of first-year students. Students must be asked about their achievement, their goals, and involvement during their first year. There are many ways to collect data on student experiences and involvement, but there is no better way to gauge where change is needed at an institution of higher education than to ask its main stakeholder-the student. Student involvement data can provide valuable information in improving aspects of higher education from academic content to involvement and retention. Assessing student expectations and needs informs faculty and administrators of how best to plan for education. Cuseo (2002) asserted that, "college-entry 
assessment becomes valuable not only as a baseline for longitudinal outcomes assessment, but also as a vehicle for helping us know who our learners are and what they are like when they enter our doors" (p. 4).

The Instruments There are various instruments currently used to measure student expectations and experiences. Each instrument provides varying ways to capture data that could lead to enhanced student success. A brief review of some of the most widely used first-year questionnaires follows.

The College Student Report (CSR) The College Student Report (CSR) was designed by a panel of leading assessment scholars for the National Center for Education Management Systems. This questionnaire is administered by the Indiana University Center for Postsecondary Research in cooperation with the Indiana University Center for Survey Research. A successful pilot of the instrument was administered in 1999, and the inaugural launch of the instrument occurred in the spring of 2000. Since that time, the College Student Report has been used by more than 850 colleges and universities and administered to over 620,000 students.

The design team of this instrument was interested in designing a survey that would be consistent with and related to college outcomes. The design team had three general criteria in mind when selecting items that might be used, including:

1. Is the item arguably related to student outcomes as shown by research?

2. Is the item useful to prospective students in choosing a college?

3. Is the item straightforward enough for its results to be readily interpretable by a lay audience with a minimum of analysis? (National Survey of Student Engagement, 2005). 
The data from the annual instrument reports on how students spend their time during their first year of college. The results reports on the students' views of the activities they are involved in, how they are doing academically, how involved they are with their coursework, and the quality of their relationships with others.

Students are asked to make judgments about their experiences by responding to 100 Likert and multiple-choice questions. The data collected from this instrument informs the institutions' stakeholders, administrators, and staff about the quality of education being provided to students and where improvement is needed. Institutions that offer opportunities for their students to be engaged in campus-wide programming and activities provide learning experiences that can enhance student success.

Your First College Year (YFCY) Your First College Year (YFCY) was created in collaboration with the Higher Education Research Institute at UCLA and Brevard College's Policy Center on the First Year of College. The YFCY survey was designed as a follow-up instrument to the CIRP Freshman Survey (CIRP) and is administered at the close of the first year. A trial YFCY was first administered in 1999, and in 2000, the inaugural instrument was administered. Since 2000, the YFCY survey has been administered to over 30,000 first-time, full-time, and first-year students; over 20,000 of these students also completed the CIRP Freshman Survey.

The YFCY provides comprehensive information on first-year students at the institutional and national levels. The YFCY survey focuses on three areas of the first year that promote student learning: involvement, retention and success. The results assist researchers and practitioners in addressing student development issues, first-year curricula and co-curricular programs, adjustment to college, and overall success. The YFCY survey results enhance 
assessment of the first college year because the information it provides about student involvement and learning furnishes the institution with feedback about elements of the first-year experience that are beneficial and those areas that require attention.

The instrument includes 27 distinct Likert, yes/no, and multiple-choice questions; 30 extra response areas are available for supplementary questions. The categories that students are asked to respond to throughout the survey include campus involvement, academic success, and satisfaction. Because the YFCY analysis relates to retention issues and the overall FYE, the results would be very useful to institutions wanting to develop a first-year program or to an institution that wanted to enhance its current program and/or retention efforts.

College Student Expectations Questionnaire (CSXQ) The College Student Expectations Questionnaire (CSXQ) is an instrument developed by the University of Indiana - Center for Postsecondary Research. This questionnaire contains 100 Likert-type items with seven scales, with the two extreme responses being, Very Often and Never, which are used in 12 sections of the CSXQ. The instrument can be completed in 10-15 minutes. It measures students' perceptions about how they will spend their first year in college. The CSXQ includes a brief welcome note in the survey that informs the students of why the survey is being administered, how students should complete the survey, and how the results will be processed. 
CIRP Freshman Survey The CIRP Freshman Survey was created in 1966 by the American Council on Education, therefore making it the oldest empirical study of entering students in higher education. According to the Higher Education Research Institute (HERI) database, where the survey is housed, more institutions utilize CIRP than any other first-year precollege instrument. The CIRP contains 40 items that provide information on freshman opinions and attitudes about their degree and career goals, their expectations of college, orientation towards college, their high school experiences, and their demographic characteristics. The CIRP has been used by more than 1,700 two-year and four-year institutions since 1966 .

The College Student Inventory (CSI-B) The College Student Inventory (CSI-B), developed by Michael L. Stratil, is a 100-item survey that requires approximately 30 minutes to complete. The results of the CSI-B are used to assist institutions in increasing student success, improving retention, and enhancing advising effectiveness. Results of the CSI-B also assist the university in gaining a better understanding of the support services that are necessary to help students succeed.

National Survey of Student Engagement (NSSE) College Student Report The NSSE instrument uses five benchmarks that address student involvement: academic challenge, active and collaborative learning, student-faculty interaction, supportive campus environments, and enriching educational experiences. The section that follows will provide and in-depth review of how the NSSE has been used to acquire critical data at MSIs across the U.S.

\section{The BEAMS Project}

How are MSIs to reduce their gap in higher education attainment without the necessary resources and infrastructure? The Building Engagement and Attainment of Minority Students (BEAMS) project is a national initiative aimed at reducing the gap in higher education for 
African Americans, Hispanic Americans, and American Indians (Bridges et al., 2005). The project began with a focus group of MSIs from around the country brought together as a consortium of MSIs to discuss student involvement and retention. The idea of consortia promotes innovation and helps sustain new practices; consortia are used to influence and support others in an effort to change areas that are not meeting expectations. The BEAMS project provides MSIs an inside track on how best to make changes that affect student learning from the student and institutional perspectives. It uses student involvement data to increase the success rates of underserved students.

The BEAMS project is a joint project of the American Association of Higher Education (AAHE) and NSSE; the Lumina Foundation for Education funds the project. Campuses involved in this project learn to use their own student data to initiate campus changes in order to build on student success. The first steps included (a) supplying MSIs with baseline data about their own students and how they currently engage in the academic environment; (2) creating an action plan that best utilizes student feedback to address areas requiring improvement, and (c) providing continued assessment over time related to student learning. The idea is to increase student involvement and attainment. However, a lack of participation in this program is related to the costs associated with the dissemination of NSSE and other instruments as well as the difficulty with institutional infrastructure. The aim of the BEAMS project is to include as many as 140 MSIs in generating strategies that increase student involvement and learning throughout the U.S.

Although the NSSE has gained popularity since its 1999 debut, one study in particular, conducted at a major doctoral-extensive southeastern institution, explored the NSSE benchmarks with regard to multiple years of student responses as they relate to student outcomes such as 
freshman retention, GPA, pursuit of graduate education, and employment outcome upon degree conferral. The results of this study indicated that the benchmarks, as grouped, lacked the power to explain how student outcomes are linked to the responses on the survey. Gordon, Ludlum, and Hoey (2008) suggested that there are other ways of using the NSSE data, and that schools should not be fixated on getting high marks on the NSSE itself, but instead seek information to better improve the learning environment for their students so that more involvement takes place.

Zhao and Kuh (2004) developed another set of measures by dismantling the benchmarks created by NSSE and looking at the data from a new perspective. The researchers focused directly on student outcomes with regard to social, practical, and academic competence. Pike (2003) also developed an alternative grouping of the NSSE items and discovered other useful information that would assist institutions regarding improvements for involvement. Student involvement, as defined by Kuh (2001), is “what the student and the institution use to prompt their use of effective educational practices" (p. 32). Students succeed by becoming involved and actively seeking opportunities on and off the campus (Astin, 1984; Pascarella \& Terenzini, 1991). Student success includes persistence, satisfaction, learning, and graduation.

\section{Creating an Environment for Involvement}

Because student retention affects a wide variety of students, it is important to create ways to assist the most vulnerable of these students, a category that mainly consists of students from underserved populations, low socioeconomic backgrounds, and commuter groups. Students who work full or part-time and have families may not receive the same support, if any, as students who come from second- and third-generation college families; it is very difficult to get and keep students involved in campus programs and/or activities during the evenings or on weekends. According to Barefoot (2000), 
Student involvement, in spite of its correlation with many positive outcomes of college, is becoming an increasingly elusive objective at institutions where all or the majority of students commute and where off-campus work is the norm rather than the exception. (p. 3)

Because of this lack of involvement, students fail to benefit from student-to-student interaction as well as the developmental components of what the first-year experience encompasses. Many minority students entering UDC, as well as colleges and universities throughout the nation, lack the skills necessary to navigate their initial year of higher education and typically do not return beyond their initial year. There are reasons why student affairs professionals place such an emphasis on program planning and encouragement of student involvement. Student involvement in university clubs and organizations, campus employment, and other activities promotes psychosocial development in students (Barefoot, 2000).

Using the Student Development Task and Lifestyle Inventory (SDTLI), Foubert and Grainger (2006) found that "involvement in clubs and organizations has been shown to correlate positively with several areas of psychosocial development" (p. 169). This was especially evident on the self-reporting survey of college juniors who are involved in student organizations. These students scored higher than non-organization members in the areas of educational involvement, career planning, lifestyle planning, cultural participation, and academic autonomy (Cooper as cited in Foubert \& Grainger, 2006).

A study conducted by Flowers (2004) was based on Astin's (1984) theory of student involvement, which suggests that student development is directly related to the amount of student involvement experiences that students have on campus. Flowers (2004) emphasized the need for student affairs professionals to encourage African-American students to participate in 
student-related activities, clubs, and organizations. Participation in clubs and organizations and other campus activities were found to positively affect African-American students' gains in vocational preparation (Flowers, 2004).

Based on the research of Terenzini, Pascarella, and Blimling (1996), the impact of college experience, which includes Greek-letter affiliation, participation in inter-collegiate athletics, and other extracurricular activities, positively affects college student development.

\section{Leveling the Playing Field for Success}

Understanding the relationship between student, environment, and involvement remains important. LaNasa, Olson, and Alleman (2007) suggested that expanded learning opportunities are at the root of student involvement; residence halls and the community that are shared in these living spaces have increasingly provided prime venues for increased involvement. Pascarella and Terenzini $(1991,2005)$ have also suggested that there is a substantial body of research that shows that residence halls have a positive, although indirect effect, on student development and growth.

Student involvement is both student driven and institution driven. The student-driven element consists of the level of effort that the student expends on educationally purposeful activities. The institution-driven element consists of how the institution utilizes its resources, organizes the curriculum, and provides other services to encourage students to participate that lead to successful outcomes, i.e., persistence, satisfaction, learning, and graduation (Astin, 1977, 1984; Chickering, 1987, 1994; Feldman \& Newcomb, 1969; Kuh, 1981; Pace, 1979; Sanford, 1962).

Kuh (2005) suggested that although the concept and benefits of student involvement have existed for years, university buy-in has not yet caused institutions to create conditions that foster 
student success. In order to create an engaging climate for all students, the institution must first have an educated understanding of its stakeholders

\section{Academic Advising}

Academic advising is considered a major component of a first-year student's college experience. Academic advising, at best, is uneven across college campuses, and it is not clearly defined. The roles and responsibilities to be assumed by many faculty members are unclear and limited in terms of the responsibilities (Habley, 2003). According to Frost (2000), there are many discrete components that work together to make academic advising more effective for students: academic advising, course scheduling, and mentoring. Each of these concepts is a good starting point for the "two historical aims of undergraduate education: to involve students with the content of their learning and to involve them with the teacher" (Frost, 2000, p. 3). Productive, effective, and intrusive advising appears to be a valuable aspect of higher education that many faculty and students take for granted, particularly during the first year.

Light (2001) suggested that advising is an integral component of higher education, the importance of which cannot be underestimated. Creators of the NSSE Annual Report (2007) asserted that "when done well, academic advising helps students to develop and act on meaningful educational plans and contributes to the institution's teaching and learning mission" (NSSE, 2007, p. 23). The content and delivery of effective academic advising suggests that academic advising was meant to be more than an occasional meeting between advisor and advisee two times per academic year. Light (2001) further suggested that "students who get the most out of college, grow the most academically, and who are the happiest organize their time to include activities with faculty members" (p. 10). Effective academic advising is supposed to address barriers and challenges that students sometimes find difficult to overcome during their 
academic careers (Light, 2001). Because academic advising is a key component in a student's academic career, Light (2001) contends that academic advising, as a college activity, shares a legitimacy that is only second to that of teaching.

A primary challenge to appropriate and productive academic advising appears to be in providing effective academic advising to students. According to Kramer (2003a), other challenges include, but are not limited to, demands upon faculty time, student response to effective advising, and a lack of student responsibility. Kramer (2003b) offered a unique perspective about what higher education is to the greater society; he stated that a more proactive view of higher education is that it is a "leader in and servant to society" (p. 2). Kramer (2003a) also suggested that faculty and academic departments join in collaborative ways to improve the institution with regard to improving the delivery of academic advising. The next section will examine the origin of academic advising and how its proponents brought advising to the forefront of higher education, especially with respect to students beginning their initial year in college.

\section{Academic advising: an historical perspective}

Academic advising once played a major role in the undergraduate experience (Kramer, 2003). Having faculty members serve as advisors dates back to 1877 when Johns Hopkins University first initiated the formalized system of faculty advising (Kramer, 2003). Other significant events that have influenced faculty advising through the mid-20th century include Harvard University's implementation of a similar advising program for its freshman students in 1888 (Kramer, 2003). The University of Illinois, in 1901, appointed its first Dean of Men to focus specifically on disciplinary matters along with extracurricular activities and to assist students with academic problems (Kramer, 2003). Following World War II, there was an even 
greater need to assist a student body that reflected diverse changes. As a result, more emphasis was placed on student-centered advising practices (Kramer, 2003).

The historical aims of undergraduate education were, (a) students should be active participants with the content of their learning, and (b) students should be involved with their teacher. Ever since higher education emerged, there has been a desire to merge students with faculty members (Kramer, 2003). The bringing together of faculty and students occurred during the arrival of American colonial colleges when academic advising had not yet been clearly defined (Kramer, 2003).

Frost (2000) discussed academic advising within the context of three defined periods of higher education. From the founding of America's first colonial institution, Harvard (1636), to the late 1890 s, Frost marked this first period as the undefined period of academic advising. During the second period (late 19th century to 1970s), academic advising was defined, but unexamined, and during the third period (1970s to current day), academic advising was both defined and examined (Frost, 2000).

Expectations of faculty grew throughout the history of higher education; the role of faculty grew to include responsibilities of not just teacher and mentor, but of researcher, writer, grant procurer, and participant in faculty governance (Habley, 2003). Faculty members are expected to assume multiple roles (Habley, 2003). There was a shift from faculty serving as sole academic advisors to counselors as evidenced at Harvard University and Johns Hopkins University. Following World War II, there was a shift, "a decided trend toward individuals other than instructional faculty delivering academic advising services" (Habley, 1992).

It was during the third period, or the 1970s, that two proponents of academic advising, Crookston and O'Banion, began to examine the link between student development theory and the 
academic advising process. The idea of developmental advising was created, and the move away from prescriptive advising began to occur. O’Banion (1972) asserted that academic advising is central to the process of higher education. He described the process of academic advising as occurring in five hierarchical steps: (a) exploration of life goals, (b) exploration of vocational goals, (c) program choice, (d) course choice, and (e) course schedule.

\section{Developmental advising vs. prescriptive advising}

Proponents of developmental advising, Crookston (1972) and O’Banion (1972) both linked their advising perspectives to student development theory, most notably, Arthur Chickering's (1969) psychosocial vectors of student development. They posited a link to three of Chickering's seven vectors of student development: developing competence, developing autonomy, and developing purpose (Gordon, 1988).

Crookston (1972) saw prescriptive learning as advisor-centered, where the majority of the responsibility is placed on the advisor. Prescriptive learning focuses on limitations of what the student can accomplish; the effort put forth on solving problems is seen as a negative, and the overall relationship between the advisor and student places the advisor in an authoritative role that evaluates the progress of the student (Crookston, 1972). There is no shared emphasis in this form of learning. Crookston's model of developmental advising may have had its roots in the student-centered theories developed throughout the post World War II years.

Crookston's developmental advising/teaching model is contrary to prescriptive learning. His model emphasizes a shared responsibility between the advisor and advisee (Crookston, 1972). Moreover, the potential of the student is a significant part of this advising relationship and fosters the questions: What does the student bring to the table? Which skills and talents? What are the student's future goals? There is equal problem solving between advisor and 
advisee; the advisor does not assume responsibility for the student's learning, and the student has an equal opportunity to develop his or her sense of self (Kramer, 2003).

Frost (1995) validated Crookston's developmental advising model when he suggested that students who are advised using this particular model tap into their responsibility as students and depend less on the planning and reliance of the academic advisor. The preferred result of the shared responsibility between advisor and advisee leads to student learning, student involvement, and assists students in planning for their own success.

Similarly, Chickering (1994) suggested that the concept of shared responsibility should exist when advising assists students in increasing their capacity to take responsibility for their own education. The relationship between student and advisor should be more than the advisor raising questions and responding to student queries. This special relationship should include sharing perceptions with students instead of creating the environment for the students, and suggesting resources instead of directing students to specific information. In effect, the advisor establishes the environment for student learning by removing limitations and focusing on the possibilities of student success.

In some respects, the academic advisor is seen as the liaison between the academic and the social aspects of a student's college career. Engaging a student in conversations that pertain to the classroom as well as to his or her involvement in student organizations may have a significant impact on how a student creates connections for life after college (Kramer, 2003).

Light (2001) expanded upon Crookston's developmental advising model by suggesting aspects of the effective advising that are student-centered. These aspects include the advisor focusing on what the students find interesting and assisting the students in making a connection between their academic course load, their own passions, and life goals. Effective advisors take 
information gleaned from the student and tailor their advising style to one that fits the needs of the student.

Light (2001) suggested that besides establishing a rapport with students, effective advising engages the student, assists students in seeing the connection between their academic coursework and their goals, as well as share with the student their own experiences with relation to the area of study. The best-suited advisors also encourage students to take responsibility for their own growth and success, as well as assess student progress.

\section{Academic advising: a shared responsibility}

Part of the advising as teaching model includes involving the entire academic community and being able to refer students to various campus resources to better serve diverse student needs. It takes a campus to graduate a student; collaboration is key (Kramer, 2003). Kramer (2003) also discussed good practices in undergraduate education: regular student-faculty contact; student cooperation and responsibility for their education; active learning, prompt feedback, reward and recognition of time on task, high expectations, and respect of diverse talents and ways of learning.

Habley and Morales (1998) collected data from the Fifth National Survey on Academic Advising Practices concerning academic advising across the country. In $48 \%$ of the campuses surveyed, faculty were the sole academic advisors for students. In $42 \%$ of the institutions, faculty advisors and staff shared advising responsibilities.

Chickering and Gamson (1987) asserted that "frequent faculty student contact in and out of the classroom is the most important factor in student motivation and involvement" (p. 4). Kramer (2003) contended that faculty advising should receive further attention from those who 
are in charge of resources and that those who are making decisions about such matters are uninformed about what effective advising entails.

According to Kramer (2003), academic advising is an area that requires much improvement, most noticeably in the following areas:

- Faculty advising practices should include evaluation of where academic advising needs improvement. (This evaluation should be conducted by students as well as faculty members and chairs that are involved in this process.)

- Faculty members should also be acknowledged for their work as well as rewarded for their part in the advising process.

- Resources and departmental support should also be provided for faculty to aid them in advising students. (p. \#)

According to the 1987 and 1998 ACT Advising Survey (Kramer, 2003), retention data, student data for individual populations, career planning resources, and final reports of the ACT Survey from previous years are not optimistic about positive gains in academic advising or its focus on quality advising. Areas that improved incrementally on surveys received between 1992 and 1998 included increased involvement of faculty and an increased tendency to regard contacts with faculty advisors as important and as information resources. Those areas where declines in faculty advising were most significant occurred in the areas of training, evaluation, and recognition and reward.

According to Habley (2003), many faculty members perceive academic advising as perfunctory and ineffective. Both good and bad examples of faculty advising can be found on any college campus. According to Habley and Morales (1998), information from ACT's Fifth National Survey of Academic Advising supported the assertion that existing problems in faculty 
advising are particular to each campus. Kramer (2003) found that only $23 \%$ of campuses nationwide require training for faculty advisors; only $29 \%$ regularly evaluate faculty member performance in academic advising, and only $31 \%$ provide any form of recognition or reward for those faculty who do advise students. This could prove to be important in the advising process because of the potential impact of the aforementioned data on one of the most important aspects of the first-year college experience.

According to Glennen, not all faculty are meant or need to be advisors (as cited in Habley, 2003). Declines in enrollment have been linked to retention and the lack of fundamental academic advising by a faculty member (Habley, 2003). According to the Carnegie Commission, the highest attrition (40\%) takes place during the freshman year. A strong academic advising system has proven to be an effective retention initiative. Glennen suggested that "good advising is critical to the life of the campus and the success of its students" (as quoted in Kramer, 2003, p. 42).

Darling and Woodside (2007) pointed out the importance of connecting teaching to academic advising as a normal extension of what the instructor does in his or her faculty position. They also examined a student's life experiences prior to college through the first year. Keup and Kinzie (2007) examined the demographics of college life and how it has changed via the NSSE and YFYC data. The researchers posed the following questions: What sort of preparation do students arrive with for their first year of college? Are they engaged in college life or not? Some arrive with an inflated sense of expectations and skill assessment. Did they come from an environment of inflated grades in high school and unrealistic academic expectations in college? The advisor's role must be consistent to handle and encourage a wide variety of concerns and issues that face first-year students. 


\section{Academic advising: the student perspective}

The previous section discussed the shared responsibility necessary in developing an ongoing conversation between student and faculty member. This section will focus on the student perspective, and the following section will discuss the faculty perspective.

According to Damminger (2007), students must learn about themselves in order to make informed decisions and choices. Intentional advising supports building relationships, assesses advisee needs, and works to provide for those needs. This practice causes deliberate discussion and self-reflection. Damminger explained, “Advisees' levels of development must be considered by the advisor in the first year and the need for additional self-awareness through assessment" (p. 60). Advisors should consider it their responsibility to assist students in moving to the next level of development. Damminger (2007) suggested that "academic advising is one component of the higher education experience that can be shared and constructed by the advisor and advisee, and fosters the development of the whole student" (p. 61). Thus, frequent interaction is necessary in order to build a relationship between advisor and advisee.

Similar to O'Banion's and Crookston's research on advising, Damminger (2007) examined academic advising from the perspective of prescriptive versus intentional advising. Prescriptive advising provides quick, simple advising and involves course selection and very little in terms of relationship development. Intentional advising should play a prominent role in the academic life of any student. Emphasis should be placed on building a relationship in which the student feels free to ask questions, and the advisor-student interaction is an extension of the classroom.

Advising/teaching may be an experience between teacher and student that contributes to the student's development and can be assessed. Damminger (2007) suggested that academic 
advisors of first-year students need to approach advising as if they are preparing a lesson plan: develop an on-going and interactive relationship, determine immediate student needs, and help students to set goals in order to meet those immediate needs. Self-awareness should be a topic of the initial meeting between advisor and advisee as well as ascertaining what the student's goals are. By following this route of advising/teaching and receiving feedback from their advisors, students begin to develop a sense of self-awareness. Their thoughts on how to incorporate this new information assists them in making informed decisions about their academic preparation in and outside of the classroom.

The use of open-ended questions by the advisor when addressing first-year students helps both the advisor and advisee in determining the best course of action toward a meaningful relationship. Academic advisors need to be aware of many different elements and student profiles in order to assess the students in making informed decisions about academic and nonacademic choices and outcomes. They need to have many types of information at their disposal and be aware of campus resources in order to refer students as needed. The advisor plays the role of getting the student to self-assess in order to move ahead.

According to Damminger (2007), “self-assessment includes awareness of one's interest, abilities, values, and learning patterns and their connection to course selection, choice of major, and occupational aspirations" (p. 63). Advising interactions should ultimately uncover and help students to see the connection between themselves, their course work, their majors, and career goals (Damminger, 2007). Student reflection helps to uncover the passion, abilities, and core values that the student possesses.

Assessment of the first year of college involves exploration. Advising should be intrusive, requiring students to respond to difficult questions about themselves and their goals. 
The relationship should begin with an emphasis on the student participating in discovery of what he or she will include in the academic plan.

The role of the advisor must be carefully explained to the advisor in order for him/her to implement successful advising practices. The advisor emphasizes the sharing relationship that must be established between the advisor and advisee; discusses the various elements involved in advising first-year students: academics, intellectual growth, health, challenges, finances, integration, involvement, and transition. As a result of this interaction, the advisor begins to understand the student from various perspectives, their challenges, concerns, and interests (Darling \& Woodside, 2007).

\section{Academic advising: faculty perspective}

Academic advising is defined through various approaches that involve developmental teaching. According to Light (2001), good advising may be the single most underestimated characteristic of a successful college experience” (p. 81). Darling and Woodside (2007) suggested that developmental advising involves helping students interact with the environment and interpersonal interaction, behavioral awareness, problem solving, decision-making, and selfevaluation. It also involves assisting students in being successful, engaging students in learning, and understanding students' diverse experiences and backgrounds. Crookston (1972) proposed that advising is essentially a teaching condition for both student and advisor. According to Habley and Morales, (1998), "nationally, less than one-third of faculty advisors receive any evaluation, much less any recognition or reward" (p. 88).

Upcraft and Stephens (as cited in Gordon and Habley, 2000) addressed the changes in demographics and characteristics of the student body over the past decades. They indicated that the major changes include: race and ethnicity, gender, age, residence, sexual orientation, changes 
in family dynamics, mental and physical health, attitudes and values, and academic preparation as well as how students finance their education. More students are working their way through college and live off campus than during the earlier part of the $20^{\text {th }}$ century. According to Darling and Woodside (2007), "the success of first-year students depends on advisors' understanding the various and diverse experiences that shape students' lives" (p. 6). Everyone involved should be able to point to those choices, activities, and philosophies that brought about change and student success. Success in the area of academic advising begins with strategic planning. The planning model should emphasize student learning, faculty comprehension of their role, and the resources available to faculty to accomplish the goals of the plan.

Faculty development includes workshops, updates, changes to curriculum, conferences, publications, and support from department, college, and/or school. Darling and Woodside (2007) suggested that "leadership requires one or more members of the organization to envision a different and better manner of achieving student success through academic advising” (p. 145).

\section{Counseling Center}

This segment of the literature review will highlight the usefulness of the campus counseling center, and its importance in proactive intervention by the campus counseling center staff in helping students to handle the transition from high school to college. This section will also examine research that focuses directly on the role of the university counseling center, an integral part of the student support system in assisting students through anxiety and helping them to persist beyond their initial year in college. Information contained in this section was compiled in order to present a synopsis of both situational concerns that students experience as well as more problematic and potentially serious symptoms that may impede student progression through college. 
UDC students, like many first-year students, are likely to begin their initial year of college with concerns and issues that may threaten their ability to persist through their first year. Adjustment difficulties of students have been an emerging issue among administrations at colleges and universities since the massacre that occurred at Virginia Tech in 2007 (Lee, Olson, Locke, Michelson, \& Odes, 2009). According to Bowman (2010), "research on the well-being of diverse college students has focused largely on adjustment processes that are specific to the college environment, such as sense of belonging and social adjustment to college" (p. 181). Many of the institution's students are first-generation college students who work full or parttime, and many have families. Some first-generation students may be discouraged by friends and family members to pursue higher education because it interferes with the overall goals of the family (Berg-Cross, Craig, \& Wessel, 1996). Many minority students, who enter UDC, as well as colleges and universities throughout the nation, lack the skills necessary to navigate their initial year of higher education and typically do not return the following year, if they complete their initial semester.

The literature indicates that the academic environment is the key to student development, satisfaction, and success. An important factor in retaining students, especially during the initial year, is the environment that has been established for them and the balance that students find in this environment (Pascarella, 1984; Pascarella \& Terenzini, 1991, Tinto, 1993). According to Astin (1991), it is not only the type of institution (i.e. small, large, public, or private) that motivates students, but how students interact within their environment that influences student success. The challenge in today's institutions "is to find ways to document the presence or occurrence of as many of these potentially critical environmental factors as possible so that their impact can be assessed" (Astin, 1991, p. 32). 


\section{University of the District of Columbia's Counseling Center}

The current configuration of UDC's Career Development and Counseling Center was established in the fall of 2005; this is the first time in many years that an actual facility was created to house the various programs, services, and resources for student use. The services offered at the Center include academic and psychological counseling, including individual and group consultation, substance abuse counseling, crisis intervention, and academic support.

Like many of the nation's public and private institutions, UDC's Counseling Center was created to be a comprehensive unit servicing large numbers of students (Anxiety Disorders Association of America (ADAA), 2007). The Center is staffed with a director who is a licensed professional counselor, two additional licensed psychologists, and a psychiatrist who visits on a weekly basis. Vocational issues are often discussed associated with concerns related to areas such as emotional or psychological issues (Lucas \& Berkel, 2005). Within the campus counseling center, mental health professionals work to assist students in relating to others, developing a positive self image, and making appropriate personal, academic and career choices.

In the spring of $2009,30 \%$ of the students seen at the Center received both counseling and psychiatric services (S. Lawson, personal communication, September 9, 2009). According to the Dr. Lawson, this was consistent with national data gathered from Counseling Center Directors from across the nation. The percentage of students receiving both counseling and psychiatric services nationwide was 26\% in 2008 (S. Lawson, personal communication, September 9, 2009). Dr. Lawson also indicated that the largest concentration of counseling focused on relationship and family problems (51\%), academic stressors (37\%), anxiety disorders (32\%), and depression (31\%). Environmental stressors, personality disorders, maladaptive 
personality patterns, grief and loss, adult children of alcoholics, and family abuse histories were also presented at the Center. (S. Lawson, personal communication, September 9, 2009).

\section{Discussion of student interaction with campus counseling centers}

The data from several studies used in this document suggest that a growing number of students are experiencing more serious problems. As of fall 2010, the numbers and indicators are trending in the same direction. Per the current Counseling and Development Center Director, maladaptive disorders are up, which is similar to national trends (S. Ledbetter, personal communication, November 29, 2010).

According to Sharkin (2006), the increase in student distress may not be due to actual student condition but rather to the perception of the college therapists. The methodology used in some of the research was based on the perspective of the therapist or retrospective data. A rise in student suicide and other campus issues may have lead some campus therapists and counseling staff members to assume that issues are more serious than they really are (Sharkin, 2006). Sharkin (2006) asuggested that the age when many mental disorders begin to appear is during the traditional college ages of 18-24 years. Sharkin (2006) also believed that the problem with previous studies reveals that: (a) the reporting time frames indicated in the studies were too short; (b) that retrospective studies bear the burden of proof, (c) changes in training may have contributed to more diagnosis of student problems, (d) that the self-reporting by clients may not reflect psychopathology, (e) and that the severity of the symptoms were not well defined.

Data gathered in retrospective studies were reviewed in the development of this section. Notably, a survey of 200 counseling center staffs was conducted by Robbins, May, and Corrazini (1985); a national survey of counseling center directors was conducted by Gallagher, Gill, and Sysco (2000); and a study was conducted by Cornish, Kominars, Riva, McIntosh, and Henderson 
(2000), which examined clients' distress levels across 6 years. Two empirical studies were also reviewed, a 13-year study conducted by Benton, Robertson, Tseng, Newton, and Benton (2003) that examined trends in counseling center clients' problems from the perspective of the therapists at the conclusion of the therapy, and a study commissioned by ADAA (2007) on the accessibility and trends of counseling services offered to students at America's top national and liberal arts colleges and universities. Because of the empirical nature of the findings of the final two studies, Benton et al. (2003) and ADAA (2007) were chosen as the framework of this section.

The two studies support one another in that the empirical data suggest that student problems have increased since the 1990s and that more counseling resources are needed to assist students. Both studies also indicate that the severity of the problems that students arrive with to the counseling center have increased, from those that include the once-considered normal developmental, academic skill, and situational problems to the more serious stress/anxiety, sexual assault, and personality disorders.

There is anecdotal evidence that growing numbers of students are experiencing more serious emotional problems (Benton et al, 2003). Much of the data included in the retrospective studies previously mentioned have been recounted by counseling center personnel. Benton et al. (2003) published the results of a 13-year study in which they found that symptom severity in college students was more severe now than in the past. However, studies utilizing client intake data indicated no significant increases in the severity of student symptoms (Benton et al., 2003). The methodology used in this study included the examination of 200 college counseling centers across 13 years from the perspective of the treating therapist at case closure (Benton et al., 2003). This study found that the number of college students who sought counseling due to depression had increased notably between 1988 and 2001. 
Sharkin (2006) suggested that the Benton et al. (2003) study lacked empirical evidence and that the severity of the conditions were not reported by case. Although Sharkin (2006) did not support the depression evidence in the Benton et al. (2003) study, Sharkin did attribute some of the current day occurrences of academic and mental health struggles of college students to the transition process and the difficulties that some students experience. It is also important to note that for minority students, the challenges of transition coupled with socioeconomic issues they may face, has the potential of increasing the challenge of completing the first year (Pascarella, 1984).

Adjustment to college sometimes requires more than what new students bring to the new experience. Sharkin (2006) suggested that "even the transition and adjustment to college, a common developmental struggle during the first year at college, are becoming more stressful than ever for many students" (p. 4). What is important is that students receive the help that they need to better enable them to proceed through their first year. According to Wlazelek and Hartman (2007), sometimes there exists a link between academic failure and psychological distress; this is why referring students to the proper resource remains so important.

According to Bishop (2002), many of the student visits to the counseling center include, but are not limited to, distress, stress, a sense of being overwhelmed, heightened anxiety, as well as various forms of depression. There are also a number of students who are reporting to counseling centers who have a previous history of mental health problems. The ADAA (2007) report emphasized that the stressors students are challenged with take a toll on the emotional and physical well being of students; these factors may ultimately influence a student's ability to persist. 
The data from the ADAA report (2007) is consistent with the 13-year study conducted by Benton et al. (2003) in that stress and anxiety experienced by students is on the rise. Within the last three decades, the increase in anxiety disorders has prompted more usage by students at both national universities as well as liberal arts campuses (ADAA, 2007). Both the Benton et al. (2003) study as well as the ADAA (2007) report indicated the seriousness that can result when seemingly normal stress and anxiety issues become potential symptoms to larger psychological problems requiring counseling attention, or potentially, medication.

According to Kitzrow (2003), the impact of mental health problems on student retention can have a profound effect on academic performance, concentration, motivation and, ultimately, persistence. Sharkin (2006) suggested that "changes in how students experience anxiety can have important implications for overall mental health because high levels of anxiety are known to contribute to physical ailments, substance abuse, depression, and impaired cognitive functioning" (p. 5). A student forced to struggle with such issues as undeveloped coping skills will more likely have difficulty remaining in school.

\section{Retention Efforts and Appropriate Counseling Interventions}

According to Twigg (2005), "an estimated 60 percent of students at public institutions fail to complete degrees within five years, and half of these students leave during the freshman year" (p. 2). According to the 2005 Consortium for Student Retention Data Exchange (CSRDE) Report on the Retention and Graduation Rates, Underrepresented Minority (URM), minority students have lower retention rates than their non-URM counterparts. The first year of college is the foundation upon which the entire academic experience is built.

In response to persistent low retention and graduation rates, retention studies conducted by Braxton (2000), Pascarella and Terenzini (1991), and Tinto (1993) have identified best 
practices involved in correcting current retention trends. These best practices include creating opportunities for growth at all levels, involvement in the environment, as well as challenging students to think analytically and formulate new ideas and opinions. For several years, UDC has worked to compile an arsenal of resources for the purposes of increasing persistence and graduation rates for its students. Through a concentrated effort and awareness that retention is a shared responsibility, the Divisions of Academic Affairs and Student Affairs have formulated a comprehensive model to involve, invigorate, and assimilate UDC students within a collaborative network for student success. Students who disconnect from their environment and are presented with developmental or psychological concerns often face barriers to success. This is when it becomes necessary to refer students to those who can offer assistance.

\section{Discussion of Appropriate Counseling Interventions, Programs, and Services}

A case study conducted by Ponterratto, Casas, Suzuki, and Alexander (2001) at Howard University, a private HBCU located in Washington, D.C., led the way in creating counseling tools and interventions for those students less likely to seek counseling on their own. Outreach and academic development programs and group therapy sessions were created for students and the university community at large. Howard's message focused on prevention and involvement. Its counseling campaign included the recruitment of student volunteers trained to support freshman students as well as trained counseling staff. This each-one-teach-one strategy was implemented through the residence halls, with campus police, and other student support areas. The involvement by students with the counseling center and its programs was so pervasive that stigmas once so closely associated with counseling slowly began to erode.

Howard University's approach to preventing student attrition focused on getting students involved in a non-threatening environment on campus. The group activities included programs 
sponsored by student counseling organizations concerning issues that affected all students (i.e., self-esteem, weight and body image concerns, eating disorders, sexual orientation, etc.). Through groups offered in the residence halls, these programs served to normalize these experiences and concerns expressed by the students involved. This social environment was significant in assisting students to reach out for help: "The group modality helps break down the stigma associated with the mental illness and seeking professional help for emotional problems" (Ponterratto et al., 2001, p. 864).

The work completed at Howard University involved preparatory training for psychotherapists and counseling personnel. Training meant adapting new strategies to the HBCU population as well as understanding the signs and various cultural nuances associated with counseling in a multicultural setting. The training was instrumental in changing the stigma associated with counseling (Ponterratto et al., 2001).

Berg-Cross et al. (1996) stated that "diverse student bodies require a wider range of culturally-sensitive techniques and approaches" when it comes to exploring issues and concerns with which they are confronted (p. 853). HBCUs must be especially careful to offer and "adopt culturally informed techniques" when providing counseling (Berg-Cross et al., 1996). These techniques must be flexible and allow for adaptability, even in a non-verbal therapeutic environment (Berg-Cross et al., 1996). Unfortunately, a number of students succumb to stigmas associated with self-disclosure of emotional, psychological, or social problems. Many students who may benefit from counseling interventions go without and are not diagnosed because they harbor such ideas (Constantine, 2006). 


\section{Psychological Counseling and Race}

Nevelle and Lily (2000) studied the relationship between racial identity and psychological distress and suggested that students who were more engaged with their racial identity reported fewer psychological symptoms than those students who felt a positive Black racial identity, yet this positive identity was influenced by "strong feelings of racial dissonance" (p. 6). According to Orbe (2004), students appear to have less transition stress when social class homogeneity exists within the student body makeup.

Students with non-pronounced disabilities attend the university, but very few ever speak with a counselor. Those students who do understand the necessity of discussing their issues with a counselor may attend prescribed sessions for a time, but their visits tend to fall short of completing the optimal number of visits (S. Ledbetter, personal communication, November 29, 2010).

According to Lucas and Hunt (2001), "individuals with the greatest symptomatic distress and who reported the largest number of interpersonal problems at intake did return for counseling after an intake session, but they tended to stop counseling prematurely" (p. 261).

Lucas and Hunt's (2001) study suggested that several reasons might be responsible for students to prematurely stop attending their prescribed visits. The crisis might have been situational in nature, and whatever prompted the visit to the center may have subsided over the weeks, thereby eliminating the need for counseling in their opinion; slow personal improvement over time may have also contributed to their preemptive adjournment. The inability to clearly communicate their concerns may also have led to some misunderstanding in the session itself. Yet another issue may have been the disclosure of personal information to a stranger who the 
student may have perceived did not understand them based on racial or cultural limitations (Lucas \& Berkel, 2005).

Ponterratto et al. (2001) suggested several key factors that are significant in understanding the client-counselor relationship, two of those factors are client motivation and client-counselor dynamics. The researchers suggested that no matter the setting where counseling occurs, practitioners must be constantly aware of the broad array of concerns that students are dealing with at any given time. To that end, the counselors should stay abreast of counseling research and strategies. According to Wlazelek and Hartman (2007), counselors must be aware of the campus climate and any role it may play in the lack of success of their students both academically and otherwise.

The concerns are real for students and may contribute to the problems that cause the students not to persist at their institution. Lucas and Berkel (2005) suggest that "students who face social or interpersonal problems may also be battling educational or vocational concerns and vice versa" (p. 262). In cases such as these, counseling center professionals should be knowledgeable about other offices for referral purposes and refer students appropriately. According to Sharkin (2006), the role of college counselors is ever expanding and requires revisiting skills and knowledge necessary to lead students toward academic and psychological success.

Multicultural counseling issues require particular attention from student affairs professionals. Although many minority and majority students may have an understanding of the various factors that form the environment on the campus, within-group diversity issues are still in the developmental stage for most traditional college students (Lucas \& Berkel, 2005). 
The researchers also questioned their use of the inventories with minority populations (Lucas \& Berkel, 2005). Sedlacek (1994) suggested that current satisfaction, needs, and vocational inventories do not take into consideration the varying value systems and outlook on life that minority populations possess, and that current inventories lack a diverse approach. Sedlacek (1994) stated, "this approach perpetuates the notion that the white worldview is the standard, and that researchers need to measure the degree to which people of color deviate from it to understand them better" (p. 264).

It is the researcher's opinion that a more realistic and in depth understanding of the complexities that lie within American cultures may reveal significant data findings that are consistent with identifying the counseling and vocational needs of minority students at both HBCUs and PWIs of higher education. How minority students form connections at their institutions as well as issues that involve racial development can be identified via more inclusive research methods.

Lucas and Berkel (2005) suggested that future studies should include the effect of student counseling upon students who have racially similar counselors and the likeliness of students to return for subsequent sessions and remain enrolled through their initial year in college. This suggestion may also indicate a student's propensity to remain in school through graduation if he or she feels involved and connected to the institutional environment.

The study conducted by Lucas and Berkel (2005) presented an interesting portrayal between the racial development of both students and their counselors depending upon which stage either the student or counselor may be in during the counseling relationship. Similarities can be drawn between the racial development stages in this study and the racial identity models of Helms (1990) and her Model of White Racial Identity and to Cross $(1971,1995)$ and his 
Model of Black Psychological Nigrescence. Both of these models illustrate a progression in student development theory that is applicable to understanding the transition and developmental stages that minorities experience.

This study and the unique interaction that exists between minorities and their counselors suggests a need for institutions to address the unique college experience of each student regardless of race or gender. A review of the literature suggests that coping strategies and making a connection may be more difficult for minority students at PWIs.

Some researchers have suggested the type of institution that African-American students choose will have a significant impact upon those students' racial and academic development. Research conducted by Greer and Chwalisz (2007) indicated that African-American students who attend an HBCU versus a PWI have a less difficult time in making connections, have better academic outcomes, and are retained at a higher percentage through graduation. AfricanAmerican students who attend an HBCU graduate at a rate of $87 \%$ from HBCUs versus $9 \%$ from PWIs.

Prillerman (1988) conducted a study that found a lack of minority status stress was a strong predictor of academic success for African-American undergraduates, even more so than SAT scores. Racial identity appears to play a larger role in retaining African-American students than what current studies indicate, and the lack of information strongly suggests a need for further inquiry in this area. This is significant for counseling representatives on college campuses around the country, even more significantly at PWIs. This particular study consisted of 203 African-American undergraduate students almost evenly divided at PWIs and HBCUs. Racial stressors in the study conducted by Prillerman (1988) were placed in five categories or sub-scales according to the Minority Students Stress Scale (MSSS). Those 
categories included environmental stressors, interpersonal stressors, intra group stressors, racerelated stressors, and achievement-related stressors. Each of these categories is significant to this research and the role that racial identity plays in the lives of millions of African-American students in America.

\section{Coping Strategies Unique to the African-American Student Population}

There are unique factors that affect the lives of African-American college students, whether they attend an HBCU or PWI. It appears that these factors and the way in which students cope with these factors appear more evident at PWIs. According to Constantine (2006), factors that specifically affect the student-to-counselor experience include: student coping strategies, academic and psychological adjustment difficulties, and discomfort with the counseling environment (especially given the race of the counselor). Other factors include students with an obvious need for counseling failing to self-disclose their needs or stopping counseling prematurely, difficulty by a student to explain his or her situation, and a lack of understanding by counselors of the various situations that plague African-American students. This is an example of when understanding student culture and background is very important. Astin (1991) found that not only could students improve their success in college through greater personal involvement, but that the institution can take steps to enhance student talent development.

Adjustment concerns and environmental obstacles during the first year of college for many first-generation students can appear to be so substantial that they may seem unbearable and impossible to overcome. As stated previously, many of these students have no reference point of what college life is about when they first begin college, and they lack sufficient support systems within their own family environments to direct them through the initial years of college. 
It is the researcher's opinion that in order for the counseling center to do what is was created to do, students must understand and be encouraged to utilize the services offered by the center. Students must also come to understand that engaging in their environment means sharing information and relinquishing fear of former stigmas. It is quite possible that many of the students who could gain the most from the services that the center offers are fearful of disclosing their problems to counselors.

\section{Summary}

According to Barefoot (2004), "retention to date has focused primarily on the characteristics of the students or the external environments" (p. 11). The key may lie in better assessment of the varied types of freshman orientation courses both by institution and longitudinal research as Goodman and Pascarella (2006) have alluded to in their research. What the research has not uncovered remains to be found in continued review and revision of the varied courses. FYE program data collection and assessment will surely reveal the aspects of the freshman orientation that affect student retention from a wide array of backgrounds, socioeconomic status, as well as educational levels when students enter college. Changes made in the pedagogy of the freshman orientation should be adaptive and reflect the constant changes in both the student population and institutional environment.

Current research indicates an agreement that retention literature lacks information that emphasizes which components of the freshman orientation contribute most to increased persistence (Barefoot, 2004; Porter \& Swing, 2006). Much of this research focuses on the overall effect of this new curricular innovation and not the individual elements of freshman orientation that affect student persistence. There seems to be a general sentiment that empirical research is lacking with regard to this area. 
The proven success of freshman orientation has so changed over the years that the question has changed from should freshman orientation be offered or mandatory to which type of freshman orientation should be offered. (Henschied, n.d.). One of the most dynamic changes in the freshman orientation has been the role that this course plays as an integrator of learning for linked courses; it serves as a building block of sorts for many other courses depending upon the type of seminar. According to the Attitudes and Motivations of First-Year Students conducted by Noel-Levitz (2007), students are receptive to assistance when they first arrive on campus; the freshman orientation can reinforce what students learn in developmental courses; courses designed by major or special topic as well as courses designed for learning communities (Henscheid, n.d.).

The UTEP story involved redefining the mission of the institution and placing a special emphasis on first-year students. Instead of trying to become an institution that it was not, UTEP began to assess students based on the quality of the students it graduated rather than its admission criteria. UTEP granted access to the people of the region and focused on upholding the cultural base, inclusion, support, and investment aspects of the university. UTEP chose to celebrate its uniqueness as an urban institution; it also chose to celebrate its students' success stories and the institution's ability to create successes with its students as well as within the institution itself.

Lessons learned from FYE research have evolved to encompass students from all socioeconomic levels, races, and backgrounds. According to Natalicio and Smith (2005), "the experience offered to first-year students at all colleges and universities is where the commitment to student success really begins" (p. 157). That highly vulnerable students enter American institutions each year have the ability to rise above their circumstances and excel to new levels is 
at the heart of the reason freshman orientation exists. Natalicio and Smith (2005) suggested that standardized tests often mask the potential of first-generation, low-income, and minority students. A critical lesson in freshman orientation research is that institutional services must be provided that address students as they enter college, no matter their level of pre-college preparation. Creating opportunities for students to become fully engaged increases their success level. This approach, combined with a campus policy that addresses the continuous improvement of the quality of its programs, permits students to compete with other students, no matter their background, from anywhere in the world.

The research is substantial in regards to how college campus programs and services can support student retention goals. Academic advising, student involvement, and student counseling services can serve as early warning systems as to whether a student remains in school or departs. There is limited research available regarding the counseling of first-year AfricanAmerican students at PWIs and HBCUs. Academic and Student Affairs practitioners may be able to better serve their students if they were provided with current and applicable research regarding engaging students in the counseling experience as well as tools to assist students in overcoming preconceived notions they may hold about the counseling process. Assisting students in overcoming their self-inflicted fears and stigmas associated with counseling would of course be the first step that many institutions could take in helping their students through difficult times.

The literature reviewed for this research is indicative of the work that remains to be done regarding assisting first-year students in transition. Information found in this document may indicate that no matter which type of institution a minority student selects, counseling issues with regard to this particular population remain poorly researched. Instruments utilized to examine 
how students interact within the college environment appear to misrepresent diverse populations, their needs, and their culture. 


\section{Chapter 3: Research Design}

This study investigated, through a researcher-designed survey instrument, whether four selected predictor variables were associated with a student's eligibility to return for the fall 2010 semester in good academic standing. The four predictor variables targeted specific aspects of the college experience. They were: enrollment in the freshman orientation course, involvement in a UDC student organization, athletics or club, utilization of student counseling services, and official meeting with academic advisors.

The four variables are discrete variables (whether they participated or not) and the criterion variable (their grade point average at the end of the semester) is interval. The demographic data collected were also used to illustrate the overall characteristics of the first-year students enrolled in their initial year at UDC. The research questions were:

Research Question \#1 Is there a relationship between enrollment in the freshman orientation course, during the initial year at UDC, and a student's eligibility to return for the fall 2010 semester in good academic standing?

Research Question \#2 Is there a relationship between belonging to a UDC student club, athletics or organization and a student's eligibility to return for the fall 2010 semester in good academic standing?

Research Question \#3 Is there a relationship between utilization of the UDC student counseling services and a student's eligibility to return for the fall 2010 semester in good academic standing?

Research Question \#4 Is there a relationship between interaction with academic advisors and a student's eligibility to return for the fall 2010 semester in good academic standing? 
Table 2 represents the survey questions by category and the statistical analysis that was used to measure each of the questions. Secondary questions were also asked in order to gain more information about the students' experiences with campus faculty and services.

Table 2

Survey Items

Research Questions/Survey Items

Statistical Analysis

RQI. Is there a relationship between enrollment in the freshman orientation

Log-linear course, during the initial year at UDC, and a student's eligibility to return for the fall 2010 semester in good academic standing?

Did you take the freshman orientation course?

Frequency

I found the freshman orientation

course useful? $1=$ Not Useful to 5 =Very Useful

Frequency

RQ2. Is there a relationship between belonging to a UDC student club,

Log-linear athletics, or organization and a student's eligibility to return for the fall 2010 semester in good academic standing?

Do you currently belong to any student clubs, or

Frequency organizations?

Do you participate in the campus work-study program?

Frequency

Membership in my club/organization has increased

my motivation to remain at UDC. (1= Strongly Disagree to $5=$ Strongly Agree $)$

Frequency

RQ3. Is there a relationship between utilization of UDC student counseling

Log-linear services and a student's eligibility to return for the fall 2010 semester in good academic standing?

Have you visited the Counseling Center?

Frequency

I have benefited from the services that I have received

from the Counseling Center. ( $1=$ Strongly Disagree to $5=$ Strongly Agree $)$

Frequency

How many times have you utilized the services of the Counseling Center?

Frequency 
My visit to the Counseling Center resolved

My problem? 1=Not at all to 5= It solved my problem

Frequency

RQ4. Is there a relationship between a official meeting with academic advisors and a student's eligibility to return for the fall 2010 semester

Log-linear in good academic standing?

Have you had an official advisor meeting with your academic advisor?

Frequency

How often have you interacted with your

Frequency

academic advisor? (1- 5 or more interactions)

How satisfactory has your experience been with your academic advisor? ( $1=$ Very favorable to $5=$ unfavorable $)$

Frequency

\section{Method}

\section{Site selection}

The site for this study was a public, comprehensive, four-year university located in the northwest quadrant of Washington, D.C. The University of the District of Columbia (UDC) was selected as the research site because it is uniquely the only public, urban, land-grant institution in the United States; because of its atypical student population (the majority of students are enrolled part time), and because of the current retention concerns. As of fall 2009, UDC had a $50.6 \%$ retention rate; a retention rate that was well below the national average of approximately 68\% (ACT, 2008, Institutional Data File for Public, Open Admissions Institutions).

\section{Pilot Study}

Following UDC IRB approval in March, the pilot study was conducted with a freshman orientation class that would not be included in the study. The survey was used to measure student perceptions about their academic environment during their initial or second semester at 
UDC. Prior to distributing the survey, the researcher introduced herself and explained the purpose and relevance of the research. She explained that the survey was strictly voluntary and that student grades would not be affected for those who chose not to participate.

Fifteen first-year students, present on the day of survey administration, agreed to participate in the pilot study. The researcher observed the students as they completed the consent form and survey. No questions were asked concerning the questions and all items of the 15 surveys were completed. The pilot survey was conducted to gather evidence of clarity of the survey.

The results of the pilot study suggested that the students understood the questions. All items were addressed by the students. Two students made comments on their survey concerning their desire to be involved in work study and a student organization. No changes were made to the survey as a result of the pilot study.

\section{Sampling procedure}

The participants were first-year students enrolled in UDC for the spring 2010 semester. Two sections of eleven 100-level and developmental courses were selected from the spring 2010 course schedule, by random number generation, to administer the survey. The five developmental education courses included: Basic Mathematics, English Fundamentals, General College Math I, Introduction to Algebra, and Reading Improvement. The six general education courses included: Biological Science I, English Composition I, Freshman Orientation, Public Speaking, Introduction to Logic, and Psychology of Adjustment. Only one section of the Psychology of Adjustment course was offered during the spring 2010 semester. The column indicating students per sections lists two numbers; these numbers represent the enrolled students per each section. The 100-level courses as well as the developmental courses were all primary 
courses where first-year students are concentrated during their initial semester (Appendix A).

During previous semesters, $75 \%$ of all entering freshman students were enrolled in a minimum of one developmental course. Table 3 indicates the courses and sections that were selected by random number generation for the study. The course numbers indicated by $(*)$ denote Community College/developmental courses.

Table 3

Course/Section Sample

\begin{tabular}{lccc}
\hline \multicolumn{1}{c}{ Course } & Course Number & $\begin{array}{c}\text { Students Per } \\
\text { Section }\end{array}$ & $\begin{array}{c}\text { Sections Offered } \\
\text { Per Course }\end{array}$ \\
\hline Basic Mathematics & $4535-005^{*}$ & $32 / 29$ & 13 \\
Biological Science I & $1401-101$ & $35 / 36$ & 4 \\
English Composition I & $1133-111$ & $25 / 29$ & 14 \\
English Fundamentals & $4133-015^{*}$ & $25 / 27$ & 14 \\
Freshman Orientation & $8800-101$ & $25 / 13$ & 12 \\
Public Speaking & $4119-115$ & $27 / 31$ & 11 \\
General College Math I & $4535-101^{*}$ & $30 / 28$ & 5 \\
Introduction to Algebra & $4535-015^{*}$ & $33 / 30$ & 12 \\
Introduction to Logic & $1167-105$ & $30 / 30$ & 19 \\
Psychology of Adjustment & $1171-137$ & 29 & 11 \\
Reading Improvement & $4133-014^{*}$ & $27 / 18$ & \\
\hline
\end{tabular}

\section{Strategy for attaining institutional approval and participant cooperation}

A letter was sent to the Vice President and Provost for Academic Affairs, as well as to the university legal counsel, requesting permission to use the name of the institution in this study, and approval to conduct research at the University of the District of Columbia. The letter of request described the purpose of the study, the research design, and discussed the potential benefits of this study for first-year student persistence.

Letters were addressed to each department chairperson requesting their approval for distribution of the survey. Once approval was granted, by the department chairperson, the 
instructors for each of the twenty-two sections were contacted requesting a date and approximately twenty minutes, during the end of each course, to explain and distribute the survey to the students. Students were given a written statement that addressed their participation as voluntary and anonymous, and that they must be at least 18-years old to participate in the study.

\section{Description of the First-Year Experience Survey (FYES)}

The FYES, created by the researcher, consists of 23 questions created to gather important information about UDC's first-year students. There are 12 questions that relate directly to the four research questions, and 11 questions that relate to student demographics. The demographic questions were provided for contextual background information that assist in the development of student profiles and focused on the differences within groups of respondents.

The FYES was created to obtain information from first-year students regarding their experiences within the UDC environment. Questions 1 and 14-23 of the FYES are demographic questions including racial identifiers, financial and immigration status, as well as when students entered the university. Questions 2 through 3 of the FYES address the freshman orientation course. Students were asked if they took the course and if they found the course useful. Because the freshman orientation course is not a mandatory course at the university, if students were not enrolled in the course, they are asked to proceed to Question 3. Questions 4 through 6 focus on student involvement in campus clubs and organizations. Students were asked to identify the type of organization to which they belonged and whether or not membership in their organization had motivated them to remain at UDC. Similarly, if a student had not participated in a club or organization, he/she was asked to proceed to the counseling section of the FYES. Questions 7 through 10 addressed frequency and usage of the counseling center. Students were asked to 
indicate (a) if they had utilized counseling center services, (b) whether or not they found the services beneficial, and (c) if their problem was resolved. If students had not utilized the center, they were directed to Question 9. Questions 11 through 13 asked students about their relationship with their academic advisor. Students were asked if they had had an official advisory meeting with their advisor, how many times they have interacted with their advisor, and if he/she felt that their advisor had been helpful or not.

\section{Data Collection Procedures}

Two sections each of eleven courses were selected by random number generation. A schedule was created by the researcher to visit each of the 21 courses prior to the conclusion of the spring 2010 semester. The researcher explained the purpose of the survey to the students as well as the benefit of their responses to the study and in support of the first-year experience. Students were informed verbally and in writing that their information would remain confidential and that individual responses would appear as an aggregate collection of the total results. Students under the age of eighteen years were permitted to participate in the survey. The researcher distributed the FYES to approximately 440 students in twenty-two sections of the randomly selected courses. Not all students who were given a survey returned a completed survey. Many of the students who were given a survey decided not to complete the survey after they had received it, or were hesitant to complete the survey because of the requirement to indicate their student identification number. Not all students were present on the days that the researcher visited the classrooms to administer the surveys. This may account for the low number of completed surveys.

During the prospectus phase of this study, there was a discussion to not include any students under the age of 18 . While the study was under review by the UDC Institutional Review 
Board (IRB), the researcher was asked to include an informed consent form for each student to sign and submit along with each completed survey. This process therefore protected any firstyear students who may have been under the age of 18 . One student who completed the survey was under the age of 18 .

\section{Proposed Statistical Analysis}

Research Questions 1 through 4 are related to those elements in the environment that may influence student persistence to the fall 2010 semester. Log-linear regression was used o see if there was an association between variables. "The log-linear model is one of the specialized cases of generalized linear models for Poisson-distributed data. Log-linear analysis is an extension of the two-way contingency table where the conditional relationship between two or more discrete, categorical variables is analyzed by taking the natural logarithm of the cell frequencies within a contingency table" (Field, 2005). Frequency analysis was also utilized to describe the discrete categories of data having yes-no response formats. Percentage analysis was used in order to represent raw streams of data for a better understanding of the collected data.

The predictor variables are nominal or ordinal variable levels. Academic standing is also a nominal variable. Given the research questions and variable levels, a log-linear analysis was calculated to answer the research questions and to identify the main effects and interaction of variables. The main effect is what the independent variables extract when averaged out against each other. It describes a situation in which the immediate influence of two variables on a third is not additive. Conversely, the presence of interactions between variables may have important implications for the interpretation of statistical models (Field, 2005). 


\section{Chapter 4: Results and Discussion}

As stated in Chapter 1, the study presented here examined the relationship between four variables and students' ability to return to school, in good academic standing, for a second year. The chapter is organized by the four specific research questions posed in Chapter 1.

The study was guided by the following research questions:

1) Is there a relationship between enrollment in the freshman orientation course, during the initial year at UDC, and a student's eligibility to return for the fall 2010 semester in good academic standing?

2) Is there a relationship between belonging to a UDC student club or organization and a student's eligibility to return for the fall 2010 semester in good academic standing?

3) Is there a relationship between utilization of the UDC student counseling services and a student's eligibility to return for the fall 2010 semester in good academic standing?

4) Is there a relationship between formal meetings with academic advisors and a student's eligibility to return for the fall 2010 semester in good academic standing?

Four independent variables were utilized in this study: enrollment in the freshman orientation course, membership in a club, athletics, or organization, utilization of the University counseling center, and interaction with academic advisor. The dependent variable in this study was a student's eligibility to return to UDC for the fall semester 2010 with a grade point average of 2.0 or higher. 


\section{Results}

\section{Sample Characteristics}

Two hundred students were included in the study. Frequencies and percentages of several of the participant characteristics are presented in Tables 4 through 11 . Following the presentation of the demographic information, the results for each research question are addressed in Tables 12-30. Participants did not complete all the items in the survey resulting in variation across survey questions. One hundred thirty seven of the participants $(68.5 \%)$ were females and $61(30.5 \%)$ were males. Two students did not indicate their gender (see Table 4). Table 4

Gender of Participating Students

\begin{tabular}{lcc}
\hline \multicolumn{1}{c}{ Gender } & $n$ & $\%$ \\
\hline Female & 137 & 68.5 \\
Male & 61 & 30.5 \\
Unidentified & 2 & 1.0 \\
Total & 200 & 100.0 \\
\hline
\end{tabular}

The majority of students, $(\mathrm{N}=122,61 \%)$ were of traditional college age (17-24 years old), but the age range was between age 17 and 62 years old (see Table 5). 
Table 5

Age of Participating Students

\begin{tabular}{lcc}
\hline \multicolumn{1}{c}{ Age } & $n$ & $\%$ \\
\hline Traditional 17-24 years & 122 & 61.0 \\
25-40 years & 53 & 26.5 \\
41 years and above & 17 & 8.5 \\
Missing & 8 & 4.0 \\
Total & 200 & 100.0 \\
\hline
\end{tabular}

The majority of participants $(\mathrm{N}=156,78 \%)$ were Black or African American. Hispanic participants were $(\mathrm{N}=19,9.5 \%)$ of the sample; $(\mathrm{N}=6,3 \%)$ did not respond to this survey question (see Table 6).

Table 6

Race/Ethnicity of Participating Students

\begin{tabular}{lcc}
\hline \multicolumn{1}{c}{ Race/ethnicity } & $n$ & $\%$ \\
\hline American Indian or Alaska Native & 6 & 3.0 \\
Asian & 6 & 3.0 \\
Black or African American & 156 & 78.0 \\
Hispanic & 19 & 9.5 \\
White & 7 & 3.5 \\
Missing & 6 & 3.0 \\
Total & 200 & 100.0 \\
\hline
\end{tabular}

The majority of participants indicated that they were single $(\mathrm{N}=168,84 \%)$. Married students followed single students with $(\mathrm{N}=17,8.5 \%)$, and $(\mathrm{N}=7,3.5 \%)$ of the participants indicated that they were divorced. Four percent of the participants did not respond to this question (see Table 7). 
Table 7

Marital Status of Participating Students

\begin{tabular}{lcc}
\hline \multicolumn{1}{c}{ Marital Status } & $n$ & $\%$ \\
\hline Single & 168 & 84.0 \\
Married & 17 & 8.5 \\
Divorced & 7 & 3.5 \\
Missing & 8 & 4.0 \\
Total & 200 & 100.0 \\
\hline
\end{tabular}

Almost half of the students $(\mathrm{N}=95,47.5 \%)$ did not complete the employment status question. Of the 105 participants who completed this item, $(\mathrm{N}=39,19.5 \%)$ indicated that they were employed fulltime. The majority $(\mathrm{N}=158,79 \%)$ of the participants indicated they were U.S. Citizens (see Table 8).

Table 8

Employment and Immigration Status of Participating Students

\begin{tabular}{lcc}
\hline \multicolumn{1}{c}{ Status } & $n$ & $\%$ \\
\hline Employment status & & \\
Fulltime 40 hours or more & 39 & 19.5 \\
Part-time & 66 & 33.0 \\
Missing & 95 & 47.5 \\
Total & 200 & $100 \%$ \\
Immigration Status & & \\
US citizen & 158 & 79.0 \\
Permanent Resident & 17 & 8.5 \\
International Student F1 visa & 18 & 9.0 \\
Missing & 7 & 3.5 \\
Total & 200 & 100.0 \\
\hline
\end{tabular}


Of the students who responded to the question about financial aid, (N=137, 68.5\%) indicated that they received federal financial aid. Slightly more than one half of the participants, $(\mathrm{N}=110,56.7 \%)$ were enrolled fulltime, while $(\mathrm{N}=84,43.3 \%)$ students indicated that they were enrolled for less than fulltime; but students reported a credit hour enrollment between a low of one credit hour and a high of 18 credit hours (see Table 9).

Table 9

Financial Aid Receipt and Current Credit Hours of Participating Students

$n$

Receive Federal Financial Aid

Yes

No

Missing

Total

Current number of credit hours

Part-time (11 credits or less)

Fulltime (12 credits or more)

Missing

Total
54

9

200

84

110

6

200
68.5

27.0

4.5

$100 \%$

56.7

100.0

Slightly more than one half of the participants had no children under the age of 18 $(\mathrm{N}=110,55 \%)$. Very few $(\mathrm{N}=4,2 \%)$ of the participants indicated that they had five or more children under the age of 18 . Frequencies and percentages on number of children under age 18 are presented in Table 10. 
Table 10

Number of Children under Age 18

\begin{tabular}{lcc}
\hline \multicolumn{1}{c}{ Number of Children under age 18} & $n$ & $\%$ \\
\hline No children & 110 & 55.0 \\
One child & 34 & 17.0 \\
Two children & 10 & 5.0 \\
Three children & 10 & 5.0 \\
Four children & 3 & 1.5 \\
Five or more children & 4 & 2.0 \\
Missing & 29 & 14.5 \\
Total & 200 & 100.0 \\
\hline
\end{tabular}

There was also a question about whether students were employed in work study during their initial year at UDC. Only $(\mathrm{N}=20,10 \%)$ students indicated that they were employed in work study. While work study opportunities assist in engaging students to campus life, if there are not enough opportunities for students, the odds increase that students will not be retained in higher numbers (see Table 11).

Table 11

Participating Students Involved in Work Study

\begin{tabular}{lcc}
\hline Participate in work study & $n$ & $\%$ \\
\hline Yes & 20 & 10.0 \\
No & 160 & 80.0 \\
Missing & 20 & 10.0 \\
Total & 200 & 100.0 \\
\hline
\end{tabular}




\section{Research Question 1}

Is there a relationship between enrollment in the freshman orientation course, during the initial year at UDC, and a student's eligibility to return for the second semester in good academic standing?

To examine this research question two types of analyses were conducted. Descriptive statistics were used to describe participants' responses to specific questions in the survey and a log-linear analysis was conducted to describe the pattern of data, main effects, and interactions among the variables.

Descriptive statistics were used to examine two questions asked of participants. Question 2 inquired: Did you take the Freshman Orientation course? Question 3 inquired: Ifound the Freshman Orientation course useful, which participants rated using the following scale: $1=$ strongly disagree, $2=$ disagree, $3=$ neither agree nor disagree, $4=$ agree, and $5=$ strongly agree. Of the 200 participants, 195 responded to question 2 (Did you take the Freshman Orientation course?), and of these, $57 \%$ had taken the course, while $40.5 \%$ had not (see Table 12).

Table 12

Frequencies and Percentages of Students Enrolled in the Freshman Orientation Course

Enrollment in the Freshman Orientation $\quad n \quad \%$

Course

\begin{tabular}{lcc}
\hline Yes & 114 & 57.0 \\
No & 81 & 40.5 \\
Missing & 5 & 2.5 \\
Total & 200 & 100.0 \\
\hline
\end{tabular}


Of those participants who took the course, 110 responded to Question 3 (I found the Freshman Orientation course useful?). Fifty one (44.7\%) of participants either agreed or strongly agreed, $23.7 \%$ that the course was useful, while $(\mathrm{N}=7,6.2 \%)$ disagreed and $(\mathrm{N}=11$, 9.6\%) strongly disagreed that the course was useful (see Table 13).

Table 13

Frequencies and Percentages of Usefulness of the Freshman Orientation Course

\begin{tabular}{lcc}
\hline Freshman Orientation Course Useful & $n$ & $\%$ \\
\hline Strongly Disagree & 11 & 9.6 \\
Disagree & 7 & 6.2 \\
Neither & 14 & 12.3 \\
Agree & 51 & 44.7 \\
Strongly Agree & 27 & 23.7 \\
Missing & 4 & 3.5 \\
Total & 114 & 100.0 \\
\hline
\end{tabular}

A log-linear analysis was conducted to determine if enrollment in freshman orientation is related to students' academic standing. A saturated or a perfect fit model was provided, $\chi^{2}(0)=$ 0.00. The model, then, suggests that the observed and expected frequencies are not statistically significantly different. The next analysis determined if any of the variables of the model could be removed. Parameter estimates were examined to interpret the main effects and the interaction among the variables. The results indicated that only two-way interactions and main effects were statistically significant. There was no main effect of freshman orientation. When comparing those who were enrolled in freshman orientation to those who were not enrolled the parameter estimate was not statistically significant $(z=-0.90, p=.370)$. There was a main effect of academic standing $(z=-4.16, p<.001)$. The majority of participants had a good academic standing $(N=149,76.4 \%)$ as compared to poor $(N=46,23.6 \%)$. The interaction between the 
variables was statistically significant, and revealed that attending freshman orientation had a direct effect on academic standing $(z=-2.36, p=.018)$ (see Table 14).

Table 14

Log-linear Parameter Index for Attending Freshman Orientation Course and Academic Standing

\begin{tabular}{lcc}
\hline \multicolumn{1}{c}{ Effect } & Coefficient & $z$ \\
\hline Enrolled in freshman orientation by academic standing & -0.87 & $-2.36^{*}$ \\
Enrolled in freshman orientation & -0.15 & -0.90 \\
Academic standing & -0.85 & $-4.16^{*}$ \\
\hline
\end{tabular}

Regarding the interaction between Freshman Orientation course and academic standing, additional analysis showed that there was an inverse relationship between the variables. More students than expected who were enrolled in freshman orientation also had poor academic standing. The cross-tabulation (Table 15) shows that 34 of the students who were enrolled in the Freshman Orientation course had poor academic standing. The null hypothesis, that there is no relationship between enrollment in the Freshman Orientation course and a student's eligibility to return for the second semester in good academic standing, is rejected. The results illustrate that participants who were enrolled in the freshman orientation course were more likely to be in poor academic standing than participants who do not take the freshman orientation course. The cross-tabulation table shows that $34(29.8 \%)$ of the students who were enrolled in the freshman orientation course had poor academic standing. The remaining $70.1 \%$ of the students who were enrolled in the freshman orientation course were in good academic standing. In contrast $14.8 \%$ of the students who were not enrolled in the freshman orientation course were in poor academic standing. Eighty-five point two percent of the students who were 
enrolled in the freshman orientation course were eligible to return in good academic standing (see Table 15).

Table 15

Observed Frequencies and Percentages of Freshman Orientation Course and Academic Standing $(N=195)$

\begin{tabular}{|c|c|c|c|}
\hline \multirow[b]{2}{*}{ Freshman Orientation Course } & \multicolumn{2}{|c|}{ Academic Standing } & Total \\
\hline & Poor $(<2.0)$ & $\operatorname{Good}(2.0 \geq)$ & \\
\hline Not Enrolled & $12(14.8 \%)$ & $69(85.2 \%)$ & $81(100 \%)$ \\
\hline Enrolled & $34(29.9 \%)$ & $80(70.1 \%)$ & $114(100 \%)$ \\
\hline
\end{tabular}

To further investigate the relationship among the variables, a 2 × 3 chi square analysis was conducted between survey question 3 (Did you find the Freshman Orientation course useful) and academic standing. The chi square between usefulness of Freshman Orientation course and academic success was not significant, $\chi^{2}(2)=1.93, p=.381$. While the majority of students agreed that the course was useful $(N=78)$ as compared to not useful $(N=20)$ or neutral $(N=15)$, students with good academic standing and students with poor academic standing did not differ in their ratings of the course. To get an accepted $\mathrm{n}$ level, the strongly agree and agree and strongly disagree and disagree portions of this question were collapsed into single categories (see Table 16). 
Table 16

Chi-Square on Usefulness of Freshman Orientation Course and Academic Success

\begin{tabular}{lcccccc}
\hline \multicolumn{1}{c}{ Variable } & $N$ & Disagree & Neutral & Agree & $\chi^{2}$ & $p$ \\
\hline Academic Standing & & & & & 1.93 & .381 \\
$\quad$ Poor & 35 & 8 & 6 & 21 & & \\
$\quad$ Good & 78 & 12 & 9 & 57 & & \\
Total & 113 & 20 & 15 & 78 & & \\
\hline
\end{tabular}

Note. $d f=2$

\section{Research Question 2}

Is there a relationship between belonging to a UDC student club, athletics, or organization and a student's eligibility to return for the second semester in good academic standing?

To examine this research question two types of analyses were conducted. Descriptive statistics were used to describe participants' responses to specific questions in the survey and a log-linear analysis was conducted to describe the pattern of data, main effects, and interactions among the variables.

Descriptive statistics were used to examine two questions asked of participants. Question 4 inquired: Do you belong to any student clubs or organizations? Question 5 inquired: Membership in my club/organization has increased my motivation to remain at UDC? Which participants rated using the following scale: $1=$ strongly disagree, $2=$ disagree, $3=$ neither agree nor disagree, 4 -agree, and $5=$ strongly agree. Of the 200 participants, 130 responded to question 4 (Do you belong to any student clubs or organizations?), and of these $\mathrm{N}=22,16.9 \%$ ) of those who responded belonged to a student club, athletics, or organization, while $(\mathrm{N}=$ 
$108,83.1 \%$ ) of those who responded did not belong to a student club, athletics, or organization (see Table 17).

Table 17

Frequencies and Percentages of Involvement in Club, Athletics, Student Organization (N=130)

\begin{tabular}{lcc}
\hline Belong to a club or organization & $n$ & $\%$ \\
\hline Yes & 22 & 16.9 \\
No & 108 & 83.1 \\
Missing & 70 & 54.0 \\
Total & 200 & 100.0 \\
\hline
\end{tabular}

Of those students who responded to involvement with a student club or organization, 21 responded to Question 5 (Membership in my club/organization has increased my motivation to remain at UDC?). Twelve (54.5\%) of the participants agreed and ( $\mathrm{N}=3,13.7 \%)$ of the sample of 21 strongly agreed that their involvement had increased their motivation to remain at UDC while $(\mathrm{N}=2,9.1 \%)$ of the sample of 21 disagreed, and $(\mathrm{N}=1,4.5 \%)$ of the participants strongly disagreed of the sample of 21 (see Table 18).

Table 18

Frequencies and Percentages of Increased Motivation to Remain at UDC

\begin{tabular}{lcc}
\hline Involvement increased motivation to remain at & $n$ & \\
UDC & & \\
\hline Strongly Disagree & 1 & 4.5 \\
Disagree & 2 & 9.1 \\
Neither & 3 & 13.7 \\
Agree & 12 & 54.5 \\
Strongly Agree & 3 & 13.7 \\
Missing & 1 & 4.5 \\
Total & 22 & 100.0 \\
\hline
\end{tabular}


A log-linear analysis was conducted to determine if belonging to a club or organization had direct or interaction effects on academic standing. A saturated or a perfect fit model was provided, $\chi^{2}(0)=0.00$. Parameter estimates were examined to interpret the main effects and the interaction among the variables. There was a main effect of belonging to a club or organization; when comparing those who belonged to a club or organization to those who did not the parameter estimate was statistically significant $(z=-5.30, p<.001)$. The majority of participants did not belong to a club or organization $(N=108,83.1 \%)$ as compared to those that did $(N=22$, $16.9 \%$ ). There was a main effect of academic standing; with more students who had a 2.0 or higher than those who did not $(z=-3.14, p<.002)$ (see Table 19).

Table 19

Log-linear Parameter Estimates, Values, and Goodness-of-Fit Index on Belonging to a Club or Organization and Academic Standing

Effect Coefficient $z$

Belonging to a club or organization *academic standing $\quad-1.25 \quad-1.78$

Belonging to a club or organization

Academic standing

Note. ${ }^{*} p<.05$.

The majority of participants had good academic standing $(73.8 \%)$ as compared to poor (26.2\%). The interaction was not statistically significant, and revealed that belonging to a club or organization did not have a direct effect on academic standing $(z=-1.78, p=.075)$. The null hypothesis, that there is no relationship between belonging to a UDC student club or organization and a student's eligibility to return for the second semester in good academic standing, is accepted (see Table 20). 
Table 20

Observed Frequencies and Percentages Belonging to a Club or Organization and Academic Standing $(N=130)$

Academic Standing

Belonging to a club or organization

Poor $(<2.0) \quad$ Good $(2.0 \geq)$

Yes

$2(9.1 \%)$

$20(90.9 \%)$

No

$32(29.6 \%)$

$76(70.4 \%)$

\section{Research Question 3}

Is there a relationship between utilization of UDC student counseling services and a student's eligibility to return for the second semester in good academic standing?

To examine this research question two types of analyses were conducted. Descriptive statistics were used to describe participants' responses to specific questions in the survey and a log-linear analysis was conducted to describe the pattern of data, main effects, and interactions among the variables.

Descriptive statistics were used to examine four questions asked of participants. Question 7 inquired: Have you visited the Counseling Center? Question 8 inquired: I have benefited from the services that I have received from the Counseling Center. Participants rated this item using the following scale: $1=$ strongly disagree, $2=$ disagree, $3=$ neither agree nor disagree, 4 -agree, and $5=$ strongly agree. Question 10 inquired: Did your visit with the Counseling Center resolve your issue? Participants rated this item using the following scale: $1=$ strongly disagree, $2=$ disagree, $3=$ neither agree nor disagree, 4 -agree, and $5=$ strongly agree. 
Of the 200 participants, 194 participants responded to Question 7 (Have you visited the Counseling Center?). Of those participants, $(\mathrm{N}=83,41.5 \%)$ had visited the counseling center and $(\mathrm{N}=111,55.5 \%)$ had not. To control for the responses of those who endorsed no, only those that endorsed yes were included in the analysis. Eighty-one participants provided the number of times they had utilized the counseling center, of which $37.3 \%$ and $27.7 \%$ had either visited the counseling center once or twice, respectfully (see Table 21).

Table 21

Frequencies and Percentages of Counseling Center Utilization $(N=194)$

\begin{tabular}{lcc}
\hline Visited the Counseling Center & $n$ & $\%$ \\
\hline Yes (one or more visits) & 83 & 41.5 \\
No & 111 & 55.5 \\
Missing & 6 & 3.0 \\
Total & 200 & 100.0 \\
\hline
\end{tabular}

Of those that had visited the counseling center, 79 responded to Question 8 (I have benefited from the services that I have received from the Counseling Center.) Of the participants who responded to this question, 35.4\% agreed and 19.0\% strongly agreed that they had benefited from the services, while $7.6 \%$ disagreed and $8.9 \%$ strongly disagreed. Of the $41 \%$ students who responded to the research question regarding their satisfaction with their visits to the counseling center, $51.8 \%$ agreed or strongly agreed that they benefited from their visit (s) (see Table 22). 


\section{Table 22}

Frequencies and Percentages of Participants Who Benefited from the Counseling Center Services $(N=83)$

\begin{tabular}{lcc}
\hline Benefited from Counseling Center & $n$ & $\%$ \\
\hline Strongly Disagree & 7 & 8.6 \\
Disagree & 6 & 7.3 \\
Neither & 23 & 27.7 \\
Agree & 28 & 33.7 \\
Strongly Agree & 15 & 18.1 \\
Missing & 4 & 4.8 \\
Total & 83 & 100.0
\end{tabular}

Seventy-nine participants responded to Question 10 (Did your visit with the Counseling Center resolve your issue?). Fifty-one percent of the participants agreed that the visit resolved the problem, and nearly 16\% disagreed (See Table 23).

Table 23

Frequencies and Percentages of Counseling Center and Resolution of Problem $(N=83)$

\begin{tabular}{lcc}
\hline Counseling Center Resolved Problem & $n$ & $\%$ \\
\hline Strongly Disagree & 7 & 8.6 \\
Disagree & 6 & 7.3 \\
Neither & 23 & 27.7 \\
Agree & 28 & 33.7 \\
Strongly Agree & 15 & 18.1 \\
Missing & 4 & 4.8 \\
Total & 83 & 100.0 \\
\hline
\end{tabular}

A log-linear analysis was conducted to determine if utilization of UDC student counseling services had direct or interaction effects on academic standing. A saturated or a perfect fit model was provided, $\chi^{2}(0)=0.00$. Parameter estimates were examined to interpret 
the main effects and the interaction among the variables. There was a main effect of utilization of UDC student counseling services. When comparing those who utilized UDC student counseling services to those who did not, the parameter estimate was statistically significant $(z=$ $2.12, p=.026)$.

The majority of participants had not utilized the counseling center, $57.2 \%$ as compared to those that had utilized the center $42.8 \%$. There was a main effect of academic standing, $(z=-$ $4.08, p=.000$ ). The majority of participants had good academic standing $76.3 \%$ as compared to poor academic standing $23.7 \%$. The interaction between the variables was not statistically significant and revealed that utilization of UDC student counseling services did not have a direct effect on academic standing $(z=-0.80, p=.426)$. The null hypothesis, that there is no relationship between utilization of UDC student counseling services and a student's eligibility to return for the second semester in good academic standing, is accepted (see Table 24).

Table 24

Log-linear Parameter Estimates, Values, and Goodness-of-Fit Index for Utilization of UDC Student Counseling Services and Academic Standing

\begin{tabular}{ccc}
\hline Effect & Coefficient & $z$ \\
\hline Utilization of UDC student counseling services*academic standing & -0.27 & -0.80 \\
Utilization of UDC student counseling services & 0.35 & $2.12^{*}$ \\
Academic standing & -1.01 & $-4.08^{*}$ \\
\hline
\end{tabular}

Note. $* p<.05$.

The majority, $73 \%$ of students who utilized the Counseling Center, were eligible to return in the fall 2010 semester and they had good academic standing. The majority (78.4\%) of students who did not utilize the Counseling Center were also eligible to return in good academic standing for the fall 2010 semester (see Table 25). 
Table 25

Observed Frequencies and Percentages of Utilization of UDC Student Counseling Services and Academic Standing $(N=194)$

Academic Standing

Utilization of UDC Counseling Services

Poor $(<2.0) \quad$ Good $(2.0 \geq)$

Yes

$22(26.5 \%)$

$61(73.5 \%)$

No

$24(21.6 \%)$

$87(78.4 \%)$

\section{Research Question 4}

Is there a relationship between interaction with academic advisors and a student's eligibility to return for the second semester in good academic standing?

To examine this research question two types of analyses were conducted. Descriptive statistics were used to describe participants' responses to specific questions in the survey and a log-linear analysis was conducted to describe the pattern of data, main effects, and interactions among the variables.

Descriptive statistics were used to examine four questions asked of participants. Question 11 inquired: Have you had an official advisory meeting with your academic advisor? Question 12 inquired: How often have you interacted with your academic advisor? Question 13 inquired: How satisfactory has your experience been with your academic advisor? Participants rated this item using the following scale: $1=$ strongly disagree, $2=$ disagree, $3=$ neither agree nor disagree, 4 - agree, and 5 = strongly agree.

Of the 200 participants, 191 participants responded to question 11 (Have you had an official advisory meeting with your academic advisor?). The majority of participants (64.4\%) had an advisory meeting with their advisor, but $35.6 \%$ had not. To control for the responses of 
those who endorsed no, only those that endorsed yes were included in the analysis. Of those that had met with their advisor, 122 responded to Question 12 (How often have you had an official advisory meeting with your academic advisor?), and of those the majority, $99.2 \%$ had one or more meetings with their advisor (see Table 26).

Table 26

Frequencies and Percentages of Academic Advisory Meeting with Advisor

\begin{tabular}{lcc}
\hline Had an official advisory meeting & $n$ & $\%$ \\
\hline Yes & 123 & 61.5 \\
No & 68 & 34.0 \\
Missing & 9 & 4.5 \\
Total & 200 & 100.0 \\
\hline
\end{tabular}

For the 121 participants who responded to Question 13 (How satisfactory has your experience been with your academic advisor), almost half of the participants indicated that their meeting was not very satisfactory $48.8 \%$ or very unsatisfactory $35.5 \%$ (see Table 27 ). Table 27

Frequencies and Percentages on Satisfaction with the Academic Advisory Meeting

\begin{tabular}{lcc}
\hline Satisfaction with advisor visit & $n$ & $\%$ \\
\hline Very Unsatisfactory & 43 & 35.5 \\
Not Very Satisfactory & 59 & 48.8 \\
Satisfactory & 6 & 4.9 \\
Very Satisfactory & 13 & 10.7 \\
Missing & 2 & 1.7 \\
Total & 123 & 100.0 \\
\hline
\end{tabular}

A log-linear analysis was conducted to determine if interaction with academic advisors had direct or interaction effects on academic standing. A saturated or a perfect fit model was 
provided, $\chi^{2}(0)=0.00$. Parameter estimates were examined to interpret the main effects and the interaction among the variables. There was a main effect for interaction with academic advisors; when comparing those who interacted with academic advisors to those who did not the parameter estimate was statistically significant $(z=-2.60, p=.009)$. The majority of participants had interacted with their advisors (64.4\%) as compared to those that had not (35.6\%). There was a main effect of academic standing $(z=-4.91, p<.001)$, the majority of participants had good academic standing (77.5\%) as compared to poor $(22.5 \%)$. The null hypothesis, that there is no relationship between interaction with academic advisors and a student's eligibility to return for the second semester in good academic standing, is accepted.

The interaction between academic standing and students' interaction with academic advisors was not statistically significant, showing academic advising did not have a direct effect on academic standing $(z=-1.85, p=.064)$ (see Table 28).

Table 28

Log-linear Parameter Estimates, Values, and Goodness-of-Fit Index for Interaction with Academic Advisors and Academic Standing Effect Coefficient $Z$

Interaction with academic advisors *academic standing $-0.72$ $-1.85$

Interaction with academic advisors $-0.44$ $-2.60 *$

Academic standing $-0.99$ $-4.91 *$

Note. $* p<.05$.

According to the current literature, student interaction with academic advisors and faculty members is considered a key component in a student's first year of college. Student responses to their interactions with their academic advisors indicated that the majority of students did meet with their academic advisor at least once during their initial year (see Table 29). 
Table 29

Observed Frequencies and Percentages of Interaction with Academic Advisors and Academic Standing $(N=191)$

Academic Standing

\begin{tabular}{lcc}
\cline { 2 - 3 } Interaction with Academic Advisor & Poor $(<2.0)$ & Good $(2.0 \geq)$ \\
\hline Yes & $33(26.8 \%)$ & $90(73.2 \%)$ \\
No & $10(14.7 \%)$ & $58(85.3 \%)$ \\
\hline
\end{tabular}

Of the 200 students who participated in the study, whether they engaged in any of the elements of the four research questions, the majority $(77.5 \%)$ were eligible to return to UDC for the fall 2010 semester (see Table 30).

Table 30

Frequencies and Percentages of Academic Standing

\begin{tabular}{lcc}
\hline & Academic Standing & $n$ \\
\hline Poor & 46 & 22.5 \\
Good & 154 & 77.5 \\
Total & 200 & 100.0 \\
\hline
\end{tabular}




\section{Chapter 5: Summary of Findings, Conclusions and Recommendations for Practice and}

\section{Future Research}

The purpose of this study was to examine the relationship between the retention of first-year students enrolled at a public HBCU and their enrollment in the freshman orientation course, belonging to a student club or organization, interaction with their academic advisor, and interaction with the university counseling center. The outcome variable in this study, persistence, is defined as a student's eligibility to return to UDC for the fall 2010 semester in good academic standing (2.0 or higher GPA). This study analyzed data using log-linear and frequency analyses. This chapter discusses conclusions and recommendations for practice and future research.

\section{Conclusions: Freshman Orientation Course}

The Null Hypothesis (HO1) stated that there is no relationship between enrollment in the freshman orientation course, during the initial year at UDC, and a student's eligibility to return for the second year in good academic standing. The null hypothesis was rejected. Descriptive statistics were used to examine question 2, which inquired: Did you take the Freshman Orientation course? Of 195 participants, 114 (58\%) had taken the course, whereas 42\% had not. Based on these results, of the 114 participants who have taken the freshman orientation course, $70 \%$ of the students were eligible to return for the fall 2010 semester; $85 \%$ of the participants who did not take the course were eligible to enroll for the fall 2010 semester.

According to current literature, first-year students who enroll in a freshman orientation course are more likely to persist to their second year as well as to graduation. The findings of this study contradict current freshman orientation research. As discussed in chapter 1, UDC does not require the freshman orientation for all students. Students self select whether they will enroll 
in this course with the exception of students in the School of Business who are required to enroll in the course. Perhaps if at risk students were targeted by student achievement measures, i.e. high school GPA, ACT and SAT scores, the benefits of the course might be revealed in the retention outcomes.

The freshman orientation course is nationally recognized as a critical bridge course for introducing high school students to their first year in college. One possible supposition as to why first-year students at UDC vary so greatly from the national research is that those students who did not enroll in the freshman orientation course may be at high risk for dropping out, but were not encouraged to take the freshman orientation course by their academic advisors, or may not have had an advisory meeting with their assigned advisor.

Another assumption is that the benefits of the course are yet to be appreciated. As mentioned in chapter two, Goodman and Pascarella (2006) suggested that longitudinal studies are the best way to identify aspects of the freshman orientation course that may promote persistence. The common goal of the first-year orientation course is to assist students with their initial change or challenges in academic expectations at the college level while transitioning to a different level of social integration. In this study, the researcher observed that students who were well beyond the transition stage, i.e., sophomores, juniors, and seniors, were permitted to be enrolled in the freshman orientation course. It is highly unusual for students beyond the first year or continuing students to be enrolled in freshman orientation.

Another assumption is that because one third of the participants in this study are over the age of 25 , they are several years removed from the traditional college age range of $18-24$, where the benefits of the course may be greater. Non-traditional students may have a different set of challenges and issues during their initial year than students who have recently graduated from 
high school. This may indicate the need for a specially designed freshman orientation course for non-traditional students.

\section{Conclusions: Involvement in a student club or organization}

The Null Hypothesis (HO2) stated: There is no relationship between belonging to a UDC student club or organizations and persistence to the second year in good academic standing. Descriptive statistics were used to examine the question. The null hypothesis, was accepted. Question 4 inquired: Do you belong to any student clubs or organizations? Of the 200 participants, 130 responded to question 4 (Do you belong to any student clubs or organizations?), and of these $17 \%$, of those who responded, belonged to a student club or organization, whereas $83 \%$, of those who responded, did not. Based on these results, of the 22 participants who have participated in a student club or organization, $91 \%$ of the students were eligible to return for the fall 2010 semester; $70 \%$ of the participants who did not belong to a club or organization were eligible to enroll for the fall 2010 semester.

Based on the literature of Tinto (1996), which posited that most students drop out of college during the first year, it was appropriate to examine the student involvement on campus within their first semester or year. Tinto's (1993) theory asserted that in order for students to progress, they must integrate and become part of the academic environment. Twenty-two students indicated that they were members of a student club or organization. In this study, the focus of student involvement in clubs or organizations was based on events and outcomes of respondents' experience during their first year of college. The short time span could have affected the student involvement outcome in this study. The organizations represented at UDC include athletics, academic, social, and Greek-letter organizations. Although popular, freshman students are unable to join Greek-letter organizations until they have accumulated 30 credit 
hours and have established the required grade point averages. The lack of participation in these organizations may be due to the fact that UDC is predominantly a commuter campus, and it has a large population of part-time students who work either part time or full time. If student priorities are off campus more than on campus, student involvement will likely not increase.

\section{Utilization of the university counseling center}

The Null Hypothesis (HO3) stated: There is no relationship between utilization of the UDC Counseling Center and persistence to students' second year in good academic standing. The null hypothesis, was accepted. Of the 200 participants, 194 participants responded to Question 7 (Have you visited the Counseling Center?). Of those participants, $43 \%$ had visited the counseling center and $57 \%$ had not. Based on these results, of the 83 participants who have utilized the University Counseling Center, $73 \%$ of the students were eligible to return for the fall 2010 semester; $78 \%$ of the participants who did not utilize the Counseling Center were eligible to enroll for the fall 2010 semester.

The majority of first year-students who utilized the resources of the Counseling Center agreed or strongly agreed (56\%) that they had benefited from their counseling experience. Although Sharkin (2006) suggested that many mental disorders begin to appear between the ages of 18-24 years, this study could be reflective of eagerness, by both traditional and non-traditional students in utilizing the services in an area sometimes considered taboo in the African-American community.

The low number of first-year students who visited the counseling center for assistance with academics or other concerns may also indicate the need for a variety of academic and other interventions. Students who did not respond to the item that queried about utilization to the Counseling Center may have received services in the counseling center that they did not want to 
divulge; since the question on counseling addressed utilization of services, students may not have offered any further data.

\section{Official student advising by student's academic advisor}

The Null Hypothesis (HO4) stated: There is no relationship between interaction with academic advisors and persistence to their second year in good academic standing? Of the 200 participants, 191 participants answered question 11 (Have you had an official advisory meeting with your academic advisor?). The majority of participants (64\%) had an advisory meeting with their advisor, but (36\%) had not. Based on these results, of the 123 participants who have had an advisory meeting with their academic advisor course, $73 \%$ of the students were eligible to return for the fall 2010 semester; $85 \%$ of the participants who did not have an advisory meeting with their academic advisor were eligible to enroll for the fall 2010 semester. The null hypothesis, was accepted.

Of the 200 participants, 191 participants answered question 11 (Have you had an official advisory meeting with your academic advisor?). The majority of participants (64\%) had an advisory meeting with their advisor, but $35 \%$ had not. Of those that had met with their advisor, 122 responded to Question 12 (How often have you interacted with your academic advisor?), and of those the majority (31\%) had one or two interactions $31 \%$ with their advisor. For those the 121 participants who responded to question 13 (How satisfactory has your experience been with your academic advisor?), 48\%) of participants expressed that their meeting was not very satisfactory and $35 \%$ indicated that their meeting was very unsatisfactory.

Light (2001) suggested that advising is an integral component of higher education, the importance of which cannot be underestimated. First-year students, overwhelmingly (84\%), indicated that the experience that they had with their academic advisor was either not very 
satisfactory or very unsatisfactory; $62 \%$ of the students had at least one or two visits with their academic advisor.

\section{Limitations}

\section{One institution}

This study was conducted on one mixed-public university campus, e.g., Community College and Flagship students remained on campus for the fall 2009 semester. The independent nature of Associate degree students' ability to persist to their second year versus that of their flagship counterparts was not studied in this research.

\section{Benefits of freshman orientation course expected too soon}

Requesting feedback about the freshman orientation course from students who are in their initial or second semester of school, may not have offered enough time for the students to reflect on the benefits of the course.

\section{Sampling procedure}

Perhaps had the distribution of the instrument gone through departments rather than individual classes, the return rate may have yielded a more generalizeable sample.

\section{Survey design left out response options}

The survey design missed some key elements. For example, options for employment should have included "Not Employed" as well as the full and part time options. Ninety-five students did not respond to the employment question. Another question on the instrument that is missing important data is the educational standing of the student's parents. Not giving participants a "High School Diploma" option excludes pertinent information necessary to assess the support system of minority students. 


\section{Small pilot study sample}

A larger pilot study group could have addressed some of the survey design options left out of the survey. Only 15 students were involved in the pilot study in March, 2011. A larger sample may have yielded questions that were not understood or needed to be reworded. A larger pilot study might also have identified some questions that were left incomplete.

\section{Freshman orientation course not limited to first year and new transfer students}

The researcher noted that while administering the survey, there was sometimes more upperclassmen enrolled in the Freshman Orientation course than first -year students. The presence of upper class students in a course meant to serve as a transition from high school to the first year of college may impeded first-year students from being open and feeling comfortable to explore their new environment with students similar to themselves.

\section{Recommendations for Practice}

Based on available data from this study, recommendations for practice for both UDC and other similar institutions would be that at risk students be identified for placement into the Freshman Orientation course and that the course be extended and span the entire first year. This would give students an additional semester of support as they transition from high school to college. It could possibly strengthen first-year student skills in English and Mathematics, therefore preparing these students for a better chance of retention through graduation.

It is also recommended that a first-year support organization be established for first-year students, who may be at risk of dropping out, so that they may engage with committed faculty and their peers in developing new programs essential for first-year student success. The criteria for membership in this organization would be high school GPA and SAT/ACT scores. If students are targeted for inclusion early, this program could change their 
trajectory for success from dropping out to graduation. This organization would be both academic and social in nature, highly structured for attendance and inclusion in activities; and would provide students with an early connection to their institution with the hope of involving students at a different level.

In order to offer first-year students the best opportunity to grow and develop, is a course made just for them. The Freshman Orientation course should only be offered to first and second semester freshman students and new transfers. This will allow first-year students to explore and communicate with students with similar challenges coming out of high school.

Although the comparative numbers of those students who did utilize the Center was lower than those who have not sought assistance, the outcomes appear to have been beneficial. What can be done right now is to examine the differences in Counseling Center usage between non-traditional and traditional student populations. In order to address some of the academic or academic anxiety issues that may plague first-year students, it may be unpopular but necessary, to house such resources outside of the Counseling Center if the Center itself presents issues related to counseling taboos. On-line or in-person tutorial support beyond academic support may also be employed, i.e., stress management, substance abuse, and study skills.

\section{Recommendations for Future Research}

The results of this study did not align with the existing literature and failed to explain why some first year students are retained for the fall 2010 semester, whereas others are not. The variables of counseling and the freshman orientation course did not have a positive effect on students' academic standing. An issue that remains largely ignored with regard to student development and persistence models is the inclusion of minority students. As mentioned in chapter 1, when Astin (1994) first considered the student population for his research, minority 
students were not included in his target audience. Future research that is more inclusive of minority students may be able to identify, to some extent, why minority students persist versus those who do not.

As indicated in the review of literature, high-priority sub groups, i.e., first-generation students, veterans, and non-traditional students, bring an entirely different set of attitudes to the academic setting. Future research could focus on tracking these students through their first year with an emphasis on special programming and targeted resources that increase success.

Another suggestion from several researchers included the use of longitudinal studies as a way to find the aspects of the freshman orientation that positively link this course to student persistence. Future research could compare cohorts of first-year students, from various institutions and compare the persistence data.

Current research indicated an agreement that retention literature lacks information that emphasizes which components of the freshman orientation contribute most to increased persistence (Barefoot, 2004). Researchers could identify varying freshman orientation courses, across institutions, via survey or small group interviews to gain more information on which aspects of the course made the most significant impact on student success.

Current literature indicated that there is a link between developmental courses and success in the freshman orientation course (Goodman \& Pascarella, 2006). This appears to be a prime area for future research due to the fact that large numbers of students entering college for the first time are required to enroll in developmental courses before they can be elevated to college-level study. Understanding how students engage in the freshman seminar course and persist beyond their initial year and developmental coursework, may lead to a better 
understanding of how students may be able to enter higher education and by-pass developmental coursework all together.

As indicated in chapter two, HBCUs as a group may differ substantially from PWIs in the academic environment that they provide for students. Nevertheless, given the broad category of HBCUs there is likely to be substantial between-institution variance. Through a more in-depth knowledge of the student profile, increased faculty involvement, and programming strategies that address students' personal, financial, and cultural differences, institutions may be able to provide students with more satisfying and varied opportunities.

Although this study did not identify those elements of the first-year experience that influence retention to the second year for UDC students, it does highlight the need for a better understanding of what students need in the academic environment in order to persist. Future research for all entering freshman could involve pre-testing for student expectations prior to entry into college. This pre-test could occur during summer high school to college programs; it could also be administered to those students enrolled as dual students (high school students enrolled in first-year courses).

The researcher's question about the freshman orientation course focused on enrollment in the course rather than performance in the course; this study does not include information about student success in the course or whether all students successfully completed the course. These are issues that could be addressed in future research.

This study did not take into account student achievement prior to enrollment and overall grade point average. The literature suggests that freshman orientation courses that are designed for specific populations may strengthen students' awareness and character and lead to 
persistence. Further research on how targeted services that are focused on improving student persistence may prove helpful in solving the retention puzzle.

Future research may also want to control for associate degree versus bachelor's degree populations. Depending on the characteristics of the students, each experience will be different. A student's success, from their day of entry to their last, also depends, to a great degree, on the willingness of institutions to be supportive of and accountable for student progress throughout the duration of their experience. If students were eligible to return for the fall 2010 semester regardless of their involvement in these aspects of the FYE, the results of this study may provide evidence that could be used to make informed decisions about how these services need to be changed at institutions similar to UDC. As student populations change, institutions must meet and challenge students where they are when they enter the university.

A prevailing factor that appears throughout this paper is the attention to the campus culture and its importance in student retention. Applicable research concerning the effect of culture upon student retention has not kept pace with the phenomenon of a vastly changed student demographic. A student's sense of connection to the institutional environment appears to be crucial for minority students in both their racial and academic development while in college.

According to the research used in the development of this document, the feeling of inclusion and relationship to one's institution appears to increase the chances of involvement not only with other campus activities, but also with the likelihood that students who initially require and engage in student services will remain engaged. 


\section{References}

ACT. (2008). ACT institutional data file. Retrieved from

http://www.act.org/research/policymakers/reports/graduation.html

Anxiety Disorders Association of America. (2007). An audit of mental health

care at U.S. colleges and universities: Focus on anxiety disorders. (2007). Retrieved from http:/www.adaa.org/Bookstore/Publications/ADAA\%20Report\%20\%20FINAL\%20embargoed.pdf

Ashley, D., Williams, J., \& Ingrum, A. (2004). I'll find a way or make one: A tribute to historically black colleges and universities. New York, NY: Harper Collins.

Astin, A. W. (1977). Four critical years. San Francisco, CA: Jossey-Bass.

Astin, A.W. (1984). Student involvement: A developmental theory for higher education. Journal of College Student Personnel, 25(4), 297-308.

Astin, A. (1991). What matters in college: Four critical years revisited. San Francisco, CA: Jossey-Bass.

Attewell, P., Lavin, D., Domina, T., \& Levey, T. (2006). New evidence on college remediation. The Journal of Higher Education, 77(5), 886-924.

Barefoot, B.O. (1998). Exploring the evidence: Reporting outcomes of first-year seminars [Monograph], The First-Year Experience and Students in Transition, 2(25), National Resource Center for the First-Year Experience and Students in Transition University of South Carolina.

Barefoot, B. O. (2000). The first year experience: Are we making it any better? About Campus, 4(6), 12-18. 
Barefoot, B. O. (2004). Higher education's revolving door: Confronting the problem of student drop out in US colleges and universities. Open Learning: The Journal of Open, Distance and E-Learning, 19(1), 9-18.

Benton, S.A., Robertson, J. M, Tseng, W. C., Newton, F. B. \& Benton, S. L. (2003).

Changes in counseling center client problems across 13 years. Professional Psychology: Research and Practice, 34(1), 66-72.

Berg-Cross, Craig, K., \& Wessel, T. (1996). Multiculturalism at historically black colleges and universities: A case study of Howard University. In J. G. Ponterratto, J. M. Casas, L. A. Suzuki, \& C. M. Alexander (Eds.), Handbook of multicultural counseling, $\left(2^{\text {nd }}\right.$ ed.; pp. 849-868). Thousand Oaks, CA: Sage Publications, Inc.

Bishop, J. B. (2002). Students with histories of counseling: Implications for counseling centers and other administrative units. Journal of College Student Development, 43(1), 130-138.

Bowman, N. A. (2010). The development of psychological well-being among first-year college students. Journal of College Student Development, 51(2), 180-200.

Braxton, J., Hirschy, S, \& McClendon, S (2004). Understanding and reducing college student departure. ASHE-ERIC Higher Education Report, 30(3).

Braxton, J. M. (2000). Reworking the student departure puzzle. Nashville, TN: Vanderbilt University Press.

Bridges, B. K., Cambridge, B., Kuh, G. D., \& Leegwater, L. H. (2005), Student engagement at minority-serving institutions: Emerging lessons from the BEAMS project. New Directions for Institutional Research, 2005(125), 25-43. doi: 10.1002/ir.137

Chickering, A. W. (1969). Education and identity. San Francisco, CA: Jossey-Bass. Chickering, A.W. (1994). Empowering lifelong self-development, AAHE Bulletin, 47(4), 3-5. 
Chickering, A.W., \& Gamson, Z. F. (1987). Seven principles for good practice in undergraduate education. AAHE Bulletin, 39(7), 3-7.

Clark, M. R. (2005). Negotiating the freshman year: Challenges and strategies among firstyear college students. Journal of College Student Development, 46(3), 296-316.

Consortium for Student Retention Data Exchange (CSRDE). (2005). Executive summary 2000-01 CSRDE report. Norman, OK: Center for Institutional Data Exchange and Analysis, The University of Oklahoma.

Constantine, M.G. (2006). Racism in mental health and education settings. In M.G. Constantine \& D.W. Sue (Eds.), Addressing racism: Facilitating cultural competence in mental health and educational settings (pp. 3-13). Hoboken, N.J.: John Wiley \& Sons.

Cornish, J. A., Kominars, K. D., Riva, M. T., McIntosh, S., \& Henderson, M. C. (2000). Perceived distress in university counseling center clients across a six-year period. Journal of College Student Development, 41(1), 104-109.

Crookston, B. B. (1972). A developmental view of academic advising as teaching. Journal of College Student Personnel, 13, 12-17.

Cross,W. E., Jr. (1971). The Negro-to-black conversion experience. Black World, 20(9), $13-27$.

Cross, W., \& Cross, W. E., Jr. (1995). The psychology of nigrescence: Revising the Cross model. In J. G. Ponterotto, J. M. Casas, L. A. Suzuki, \& C. M. Alexander (Eds.), Handbook of Multicultural Counseling (pp. 93-122). Thousand Oaks, CA: Sage Publications.

Cuseo, J. (n.d.). The empirical case for the positive impact of the first-year seminar research on student outcomes. Retrieved from http:/www.uwc.edu/administration/ 
academicaffairs/esfy/cuseo/Empirical $\% 20$ Case $\% 20$ for $\% 20$ the $\% 20$ Positive $\% 20$ Impact $\% 2$ 0of\%20the\%20FirstYear\%20Seminar\%20Research\%20on\%20Student\%20Outcomes.doc

Cuseo, J. (2002). Organizing to collaborate: A taxonomy of higher education practices for promoting interdependence with in the classroom, across the campus, and beyond the college. Stillwater, OK: New Forums Press.

Damminger, J. K. (2007). Self-assessment: Relevance and value in first-year advising. In M. S., Hunter, B. McCalla-Wriggins, \& E. R. White (Eds.), Academic advising: New insights for teaching and learning in the first year (pp. 59-68) [Monograph] 46, Columbia, SC: University of South Carolina, National Resource Center for The FirstYear Experience and Students in Transition.

Darling, R., \& Woodside, M. (2007). The academic advisor as teacher: First-year transitions. In M.S. Hunter, B. McCalla-Wriggins, \& E. R. White (Eds.). (2007). Academic advising: New insights for teaching and learning in the first year (pp. 5-17), [Monograph] 46, Columbia, SC: University of South Carolina, National Resource Center for the FirstYear Experience and Students in Transition.

Deil-Amen, R. (2011). Socio-academic integrative moments: Rethinking academic and social integration among two-year college students in career-related programs. The Journal of Higher Education, 82(1), 54-91.

DeSousa, D. J., \& Kuh, G. D. (1996). Does institutional racial composition make a difference in what Black students gain from college? Journal of College Student Development, 37(3), 257-267.

Feldman, K. A., \& Newcomb, T. M. (1969). The impact of college on students: An analysis of four decades of research. London, UK: Jossey-Bass. 
Field, A. (2005). Discovering statistics using SPSS, (2 ${ }^{\text {nd }}$ ed). Thousand Oaks, CA; Sage Publications.

Fleming, J. (1984). Blacks in college. San Francisco, CA: Jossey-Bass.

Folger, W. A., Carter, J. A. \& Chase, P. B. (2004). Supporting first-generation college freshmen with small group interventions. College Student Journal, 38(3), 472-477.

Flowers, L. \& Pascarella, E. T. (1999). The effects of college racial composition on African American college students' orientations toward learning for self-understanding. Professional Educator, 22(1), 33-47.

Flowers, L. (2004). Examining the effects of student involvement on African American college student development. Journal of College Student Development, 45(6), 633-654. Retrieved from http://muse.jhu.edu/journals/journal_of_college_student_development/v045/45.6f lowers.pdf

Foubert, J. D. \& Grainger, L. (2006). Effects of involvement in clubs and organizations on the psychosocial development of first-year and senior college students. NASPA Journal, 43(1), 166-182.

Frost, S. H. (1995). Designing and implementing a faculty-based advising program. NACADA Journal, Monograph Issue 1, 27-32.

Frost, S. H. (2000). Historical and philosophical foundations for academic advising. In V. N. Gordon \& W. R. Habley, (Eds.), Academic advising: A comprehensive handbook (pp. 317). San Francisco, CA: Jossey-Bass.

Gallagher, R. P., Gill, A. M., \& Sysco, H. M., (2000). National survey of counseling center directors 2000. Alexandria, VA: International Association of Counseling Service. 
Gilardi, S., \& Guglielmetti, C. (2011). University life on non-traditional students: Engagement styles and impact on attrition. The Journal of Higher Education, 82(1), 33-53.

Goodman, K. \& Pascarella, E. T. (2006). First-year seminars increase persistence and retention: A summary of the evidence from how college affects students. Peer Review, $8(3), 26-28$.

Gordon, V. N. (1988). Developmental advising. In W.R. Habley (Ed.), The status and future of academic advising: Problems and promise (pp. 107-118). Iowa City, IA: The ACT National Center for the Advancement of Educational Practices.

Gordon, V. N. (1989). Origins and purposes of the freshman seminar. In M. L. Upcraft \& J. N. Gardner (Eds.), The freshman year experience (pp.183-197). San Francisco, CA: JosseyBass.

Gordon, J., Ludlum, J., \& Hoey, J. (2008). Validating NSSE against student outcomes: Are they related? Research in Higher Education, 49(1), 19-39.

Greer, T. M. \& Chwalisz, K. (2007). Minority-related stressors and coping processes among African American college students. Journal of College Student Development, 48(4), 388404.

Habley, W. R. (1992). Fulfilling the promise? Final report of the fourth national survey on academic advising. Iowa City, IA: The American College Testing Program.

Habley, W. R. (2003). Faculty advising: Practice and promise. In G.L. Kramer (Ed.), Faculty advising examined: Enhancing the potential of college faculty as advisors (pp. 23-39). Bolton, MA: Anker Publishing Company, Inc. 
Habley, W. R., \& Morales, R. H (1998). Current practices in academic advising: Final report on ACT's fifth national survey of academic advising, Monograph Series, 6, Manhattan, KS: National Academic Advising Association.

Helms, J. E. (Ed.). (1990). Black and White racial identity: Theory, research, and practice. New York, NY: Greenwood.

Henscheid, J.M. (n.d.). First-year seminars in learning communities: Two reforms intersect, Retrieved from http://www.sc.edu/fye/publications/monograph/ monographs/pdf/intro39.pdf

Hunter, M. \& Linder, C. (2005). First-year seminars. In M. Upcraft, J. Gardner, \& B. Barefoot (Eds.), Challenging and supporting the first-year student: A handbook for improving the first year of college (pp. 275-291). San Francisco, CA: Jossey-Bass.

Hunter, M. S., Henscheid, J. \& Mouton, M. (2007). Collaborations beyond the advising office. In M.S. Hunter, B. McCalla-Wriggins, \& E. R. White (Eds.), Academic advising: New insights for teaching and learning in the first year [Monograph], 46, (pp. 99-111). Columbia, SC: University of South Carolina, National Resource Center for the First-year Experience and Students in Transition.

Ishitani, T. (2006). Studying attrition and degree completion behavior among firstgeneration college students in the United States. The Journal of Higher Education, $77(5), 861-885$.

Keup, J.R. \& Kinzie, J. (2007). A national portrait of first-year students. In M. S., Hunter, B. McCalla-Wriggins, \& E.R., White (Eds.). Academic advising: New insights for teaching and learning in the first year [Monograph] 46, pp. 5-17, Columbia, SC: 
University of South Carolina, National Resource Center for The First-year Experience and Students in Transition.

Kitzrow, M.A. (2003). The mental health needs of today's college students: Challenges and recommendations. NASPA Journal, 41(1), 165-179.

Kramer, G. L. (2003a). Faculty advising examined: Enhancing the potential of college faculty as advisors (Ed.). Bolton, Massachusetts: Anker Publishing Company, Inc.

Kramer, G.L. (2003b). Advising as teaching. In G. L. Kramer (Ed.), Faculty advising examined: Enhancing the potential of college faculty as advisors (pp. 1-22). San Francisco: JosseyBass

Kuh, G. D. (1981). Indices of quality in the undergraduate experience. AAHE-ERIC/Higher Education Research, Report No. 4. Washington, D.C.: American Association for Higher Education.

Kuh, G.D. (2001). Assessing what really matters to student learning: Inside the National Survey of Student Engagement. Change, 33(3), 10-17.

Kuh, G. D. (2005). Student engagement in the first year of college. In L. Upcraft, J. Gardner, B. Barefoot \& Associates (Eds.). Challenging \& supporting the first-year students: A handbook for improving the first year of college (pp. 86-107). San Francisco, CA: Jossey-Bass.

Kuh, G.D., Cruce, T.M., Shoup, R., Kinzie, J., \& Gonyea, R.M. (2008). Unmasking the effects of student engagement on first-year college grades and persistence. The Journal of Higher Education, 79(5), 540-563.

Kuh, G., Gonyea, R., \& Palmer, M. (n.d.). The disengaged commuter student: Fact or fiction? Retrieved from http://nsse.iub.edu/pdf/commuter.pdf 
Kuh, G.D., Kinzie, J., Buckley, J., Bridges., \& Hayek, J.C. (2007). Piecing together the student success puzzle: Research, propositions, and recommendations. ASHE Higher Education Report, 32(5). San Francisco: Jossey-Bass.

Lanasa, Olson, \& Alleman (2007). The impact of on-campus student growth on first-year student engagement and success. Research in Higher Education, 48(8), 941-966.

Lane, J. E., \& Brown, M. C. (2003). Looking backward to see ahead: Implications for research, policy, and practice. New Directions for Institutional Research, 2003(118), 1-6. doi: $10.1002 /$ ir.78

Lee, D., Olson, E. A, Locke, B, Michelson, S. T., \& Odes, E. (2009). The effects of college counseling services on academic performance and retention. Journal of College Student Development, 50(3), 305-319.

Light, R. J. (2001) Making the most of college: Students speak their minds. Cambridge, MA: Harvard University Press.

Lucas, M. S. \& Berkel, L. A (2005). Counseling needs of students who seek help at a university counseling center: A closer look at gender and multicultural issues. Journal of College Student Development, 46(3), 251-266.

Lucas, M. S. \& Hunt, P. (2001, September). Commitment to career exploration in career counseling: Obstacles and facilitators. Poster presented at World Congress of the International Association for Educational and Vocational Guidance, Paris.

Mabeus, C. (2007, June 13). District's schools among worst in graduation rates. The Examiner. Retrieved from http://www.examiner.com/a777751 District_s_schools_ among_worst_in_graduation_rates.html 
Mammary, A. (2003). Interventions: An all-woman first year college seminar. Feminist Studies, 29(2), 453-460.

Martinez, J. A., Sher, K. J. Krull, J. L., \& Wood, P.K. (2009). Blue-collar scholars? Mediators and moderators of university attrition in first-generation college students. Journal of College Student Development, 50(1), 87-103.

Mattanah, J.F, Ayers, J.F., Brand, B. L., Brooks, L. J., Quimby, J. L. \& McNary, S. W. (2010). A social support intervention to ease the college transition: Exploring main effect and moderators. Journal of College Student Development, 51(1), 93-108.

Natalicio, D. S. \& Smith, M. (2005). Building the foundation for first-year student success in public, urban universities: A case study. In L. Upcraft, J. Gardner, B. Barefoot, \& Associates (Eds.). Challenging \& supporting the first-year students: A handbook for improving the first year of college (pp. 155-175). San Francisco, CA: Jossey-Bass.

National Survey of Student Engagement Annual Report (2005). Exploring different dimensions of student engagement. Bloomington, IN: Indiana University, Center for Postsecondary Research.

National Survey of Student Engagement Annual Report (2007). Experiences that matter: Enhancing student learning and success. Bloomington, IN: Indiana University, Center for Postsecondary Research.

National Survey of Student Engagement Annual Report (2008). Promoting engagement for all students: The imperative to look within. Bloomington, IN: Indiana University, Center for Postsecondary Research. 
Nevelle, H. \& Lily, R. (2000). The relationship between racial identity cluster profiles and psychological distress among African American college students. Journal of Multicultural Counseling and Development, 28(4), 194-207.

Noel-Levitz (2007). National freshman attitudes report: National research study. Retrieved from https://www.noellevitz.com/documents/shared/Papers and Research/2007/2007\%20Fres hman\%20Attitudes.pdf

Noel-Levitz (2010). National freshman attitudes report; National research study. Retrieved from https://www.noellevitz.com/documents/shared/Papers and_Research/2010/FreshmanAttit udes 10.pdf

O’Banion, T. (1972) An academic advising model. Junior College Journal, 42(6), 62-69.

Orbe, M. (2004). Negotiating multiple identities within multiple frames: An analyses of firstgeneration college students. Communication Education, 53(2),131-149.

Pace, R. (1979). Measuring outcomes of college. San Francisco: Jossey-Bass

Pascarella, E. (1984). College environmental influences on students' educational aspirations. Journal of Higher Education, 55(6), 751-771.

Pascarella, E.T., \& Terenzini, P. T. (1991). How college affects students: Findings and insights from twenty years of research. San Francisco, CA: Jossey-Bass.

Pascarella, E.T., \& Terenzini, P. T. (2005). How college affects students: A third decade of research, ( $2^{\text {nd }}$ ed.). San Francisco, CA: Jossey-Bass.

Pike, G. R. (2003, May). Measuring quality: A comparison of U.S. News rankings and NSSE benchmarks. Paper presented at the annual meeting of the Association for Institutional Research, Tampa, FL. 
Ponterratto, J.G., Casas, J.M, Suzuki, L.A., \& Alexander, C.M. (Eds.). (2001). Handbook of multicultural counseling ( $2^{\text {nd }}$ Ed.). Thousand Oaks, California: Sage Publications, Inc.

Pope, M. (1998). The relationship between psychosocial development and racial identity of black college students. Journal of College Student Development, 39(3), 273-282.

Porter, S. R. \& Swing, R.L. (2006). Understanding how first-year seminars affect persistence. Research in Higher Education, 47(1), 89-109.

Prillerman, S. L. (1988). Coping with a stressful transition. A prospective study of Black student adjustment to a predominantly White university. (Doctoral dissertation). University of California, Los Angeles.

Robbins, S. B., May, T. M., \& Corrazini, J. G. (1985). Perceptions of client needs and counseling center staff roles and functions. Journal of Counseling Psychology, 32(4), 641-644.

Sanford, N. (1962). The developmental status of freshman. In N. Sanford, (Ed.), The American college: A psychological and social interpretation of the higher learning (pp. 253-282). New York, NY: John Wiley and Sons.

Sedlacek, W. (1994). Issues in advancing diversity through assessment. Journal of Counseling and Development, 72(5), 549-553.

Sharkin, B.S. (2006). College students in distress: A resource guide for faculty, staff, and campus community. New York, NY: The Haworth Press

Shuetz, P. (2008). Developing a theory-driven model of community college-student engagement. New Directions for Community College, 144(Winter), 1-114.

Spady, W. G. (1971). Dropouts from higher education: Toward an empirical model. Interchange, 2(3), 38-62. 
Swing, R. (2003). First-year student success: In search of best practices $7^{\text {th }}$ Pacific Rim, First Year in Higher Education Conference QUT Gardens Point Campus July 10, 2003.

Terenzini, P. T., Pascarella, E. T., \& Blimling, G. S. (1996). Students' out-of-class experiences and their influence on learning and cognitive development: A literature review. Journal of College Student Development, 40(5), 610-623.

Terenzini, P. T. \& Wright, T. (1987a). Influences on students' academic growth during four years of college. Research in Higher Education 26(2),161-79.

Terenzini, P. T. \& Wright, T. (1987b). Students' personal growth during the first two years of college. Review of Higher Education 10(3), 259-71.

Tinto, V. (1975). Dropout from higher education: A theoretical synthesis of recent research. Review of Educational Research, 45(1), 89-125.

Tinto, V. (1993). Leaving college: Rethinking the causes and cures of student attrition. $\left(^{\text {nd }}\right.$ ed.). Chicago, IL: The University of Chicago Press.

Tinto, V. (1996). Reconstructing the first year of college. Planning for Higher Education, $25(1), 1-6$.

Tobolowsky, B. F., Mamrick, M., \& Cox, B. E. (2005). The 2003 national survey on first-year seminars. [Monograph], 41. Columbia, SC: National Resource Center for The Freshman Year Experience, University of South Carolina

Twigg, C.A. (2005). Increasing success for underserved students: Redesigning introductory courses. [Monograph]. The National Center for Academic Transformation.

University of the District of Columbia (2007). Enrollment profile report. Office of Institutional Research, Assessment and Planning. 
University of the District of Columbia (2009). Office of Institutional Research, Assessment and Planning: Enrollment Profile Report, Fall, 2009

University of the District of Columbia, Office of Institutional Research, Assessment and Planning: OIT Frozen Data Dump (Spring 2011).

University of the District of Columbia (2009). First-time entering freshman retention enrollment profile report. Office of Institutional Research, Assessment and Planning.

University of the District of Columbia (n.d.). About UDC. Retrieved from http://www.udc.edu/welcome/history.htm

Upcraft, M. L., Gardner, J., \& Associates (1989). The freshman year experience: Helping students survive and succeed in college. San Francisco, CA: Jossey-Bass.

Upcraft, M. L., Gardner, J., Barefoot, B., \& Associates (2005). Challenging \& supporting the first-year students: A handbook for improving the first year of college. San Francisco, CA: Jossey-Bass.

Upcroft, M. L. \& Schuh, J.H. (2001). Assessment practice in student affairs: An application manual. San Francisco, CA: Jossey-Bass.

U.S. Department of Education, National Center for Education Statistics (2002). Non-traditional undergraduates. Retrieved from http:/nces.ed.gov/programs/coe/2002/ analyses/nontraditional/

U.S. Department of Labor, Bureau of Labor Statistics. (2010). College enrollment and work activity of 2005 high school graduates (9 \# USDL\#-10-0533). Retrieved from http://www.bls.gov/news.release/hsgec.nr0.htm 
Vowell, F., \& Farrer, P.J. (2003). Expectations and training of faculty advisors. In Kramer, G. L. (Ed.), Faculty advising examined: Enhancing the potential of college faculty as advisors (pp. 55-80). Bolton, Massachusetts: Anker Publishing Company, Inc.

Wilson, R., Gaff, J., Dienst, R, Wood, L., \& Bavry, J. (1975). College professors and their impact on students. New York, NY: Wiley-Interscience.

Wlazelek, B. \& Hartman, K. (2007). Counseling for success: Assisting students in academic jeopardy. In J. A., Lippincott \& R. B., Lippincott (Eds.), Special populations in college counseling: A handbook for mental health professionals (pp.173-185). Alexandria, VA.: American Counseling Association.

Zhao, C. \& Kuh, G. D. (2004). Adding value: Learning communities and student engagement. Research in Higher Education, 45(2), 115-138. 


\section{Appendix A WVU IRB Approval Letter}

\section{W-WestViriginiaUniversity. \\ Office of Research Compliance}

\section{Expedited-IRB Protocol-Exemption}

To: $\quad$ Jones, Elizabeth

From: $\quad$ WVU Office of Research Compliance

Date: $\quad$ Friday, March 19, 2010

Subject: Exemption Acknowledgement

Tracking \#: $\mathrm{H}-22294$

Title: $\quad$ Creating an Environment of Persistence for First-Year Students at the University of the District of Columbia.

The above-referenced study was reviewed by the West Virginia University Institutional

Review Board (IRB) and was granted exemption in accordance with 45 CFR 46.101(2).

This protocol was reviewed using the following:

This research study was granted an exemption in accordance withResearch that involves educational tests, survey procedures, interview procedures, or observation of public behavior [45 CFR 46.101(2)].210r was used for this review. Please note that the IAA page should be marked Yes rather than No, since you are indeed requesting an IAA.

The following documents have been acknowledged for use in this study and are available in the BRAAN system:

The IAA is approved. Surveys, Questionnaires, Interviews Attachments Survey Questions.doc First-Year Experience Survey Miscellaneous Attachments Attachments Informed Consent FormREV.doc Informed Consent IRBNetDocument.pdf UDC IRB Approval Letter scan0005.tif Letter to Students UDCWVUCollabForm.rtf WVU Collaboration Form

Thank you.

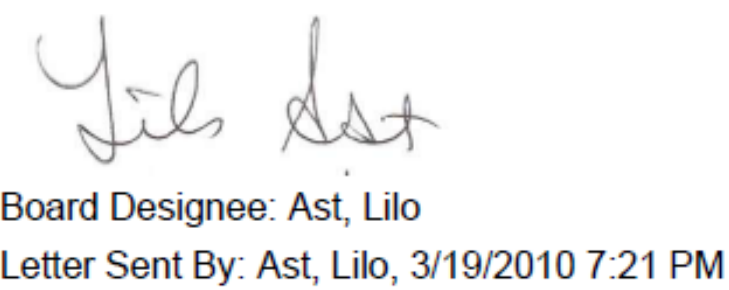




\title{
Appendix B UDC Approval Letter
}

\author{
AGREEMENT \\ between \\ UNIVERSITY OF THE DISTRICT OF COLUMBIA
}

and

TWYLA JONES

This agreement is entered into between the University of the District of Columbia ("University") and Twyla Jones ("Researcher") to conduct a study for the improvement of instruction at the University ("Study") pursuant to 20 C.F.R. § 99.31(6)(i)(C).

The parties agree as follows:

1. Purpose. The Study is being conducted to identify relationships between participation in various University on-campus events, organizations, and resources by first year students, and the eligibility of those students to return as second-year students in good academic standing.

2. Scope. The Study will involve the voluntary participation of first year students who belong to selected first-year courses. Researcher will speak to the students in class and explain the study, then elicit volunteers who will fill out a written survey that measures participation in various University on-campus events, organizations, and resources. The students will include personally identifiable information on the surveys, which will allow Researcher to compare responses to the surveys with volunteers' first-year semester and cumulative grade point averages (GPAs). In accordance with the terms of this agreement, the University will make available to Researcher the GPAs of students who have participated in the study.

3. Duration. This study shall be completed over the course of academic year 2009-2010.

4. The use of personally identifiable information in educational records obtained by Researcher shall be used for no other purpose than is necessary for the completion of the Study.

5. All records containing personally identifiable information shall be kept confidential and secure by Researcher at all times. The Study shall be conducted in a manner that does not permit personal identification of students by non-University individuals other than the Researcher. 
6. Any information obtained during the study which may be used to identify the student shall be destroyed when no longer needed for the purposes for which the study was conducted;

UNIV. OF THE DISTRICT OF COLUMBIA

TWYLA JONES

By: Graeme Baxter

Provost \& Vice President for Academic Affairs

Date:

Date:

(Signed copy on file) 


\section{Appendix C First-Year Experience Survey}

\section{First-Year Experience Survey Student ID Number}

This survey is part of an on-going effort to understand the effectiveness of the freshman year experience, to improve the services, where necessary, as well as to gain a better understanding of your experience at UDC. This survey is voluntary. If you choose to participate in this survey, individual responses will remain confidential. All student responses and results will appear as aggregate information; you will not be personally identifiable via your responses. Student responses will be coded and used in cooperation with semester and cumulative grade point averages following the grading period of the spring 2010 semester. Thank you for your participation.

1. Which semester did you enter the university?

\section{Freshman Orientation}

2. Did you take the Freshman Orientation course? Circle one. Yes or No

If you have not enrolled in Freshman Orientation, skip to Question 4.

3. I found the Freshman Seminar course useful?

1=Strongly Disagree 2 =Disagree $3=$ Neither Agree or Disagree 4 =Agree $5=$ Strongly Agree

\section{$\underline{\text { Student Engagement }}$}

4. Do you currently belong to any student club (s) or organization (s)?

If yes, please check the type of club (s) or organization (s) to which you belong (check all that apply).

If you do not belong to a club or organization, please skip to Question 6.

Undergraduate Student Government Association __ Honor Society

Cultural/Ethnic-Related organization __ Academic Greek-letter organization

Work study __ Other club or organization (please specify)

5. Membership in my club (s) or organization (s) has increased my motivation to remain at UDC? Circle one.

1=Strongly Disagree $2=$ Disagree $3=$ Neither Agree or Disagree $4=$ Agree $5=$ Strongly Agree

6. Do you participate in the campus work study program? Circle one. Yes or No

\section{Counseling Center}

7. Have you visited the Counseling Center? Circle one. Yes or No 
If you have not utilized the Counseling Center, please skip to Question 11.

Student ID Number

8. I have benefited from the services that I have received from the Counseling Center? Circle one.

1=Strongly Disagree 2 =Disagree $3=$ Neither Agree or Disagree 4 =Agree 5 =Strongly Agree

9. How many times have you utilized the services at the Counseling Center? Circle one.

$$
\begin{array}{lllll}
1 & 2 & 3 & 4 & 5
\end{array} \text { or more interactions }
$$

10. My visit to the Counseling Center resolved my problem?

1=Strongly Disagree 2 =Disagree $3=$ Neither Agree or Disagree $4=$ Agree $5=$ Strongly Agree

\section{$\underline{\text { Academic Advising }}$}

11. Have you had an official advisory meeting with your academic advisor? Yes or No

If you have not had an official advisory meeting with your academic advisor, please skip to Question 14.

12. How often have you interacted with you academic advisor? Circle one.

$$
\begin{array}{lllll}
1 & 2 & 3 & 4 & 5 \text { or more interactions }
\end{array}
$$

13. How satisfactory was your experience been with your academic advisor?

1= Very Satisfactory 2 = Satisfactory 3 = Not Very Satisfactory $4=$ Very Unsatisfactory

Are there any brief comments that you would like to share concerning your academic advising experience? (Please write your comments here.)

14. Age

15. Gender: Male Female

16. Current Marital Status Circle one. Single Married Divorced

17. Number of Children (under 18-years of age)

18. Employment Circle one: Full time (40 hours or more per week) Part Time (less than 40 hours per week)

19. What is your racial or ethnic identification? Select all that apply.

American Indian or Alaska Native

Asian

Black or African American
Hispanic

Native Hawaiian or Other Pacific Islander White 


\section{Student ID Number}

20. Which of the following best describes your current immigration status?

U.S. Citizen

Permanent Resident

International Student (F1 Visa Holder)

Other Non-Immigration Visa

21. Do you currently receive any type of federal financial aid? Circle one. Yes

No

22. How many credit hours are you enrolled in this semester?

23. What are your parents' highest levels of formal education?

Mother

Associate Degree

Bachelor's Degree

Master's Degree

Doctorate
Father

Associate Degree

Bachelor's Degree

Master's Degree

Doctorate

Thank you for your participation!

\footnotetext{
John H.

Virginia University Libraries,

ou=Acquisitions Department,
email=John.Hagen@mail.wvu.edu 